\title{
Virus Like Particles: A Self-Assembled Toolbox for Cancer Therapy
}

Arezoo Shahrivarkevishahi ${ }^{a}$, Laurel M. Hagge ${ }^{a}$, Olivia R. Brohlin ${ }^{\mathrm{a}}$, Sneha Kumari ${ }^{\mathrm{a}}$, Ryanne Ehrman ${ }^{\mathrm{a}}$, Candace Benjamin ${ }^{\mathrm{a}}$, Jeremiah J. Gassensmith ${ }^{\mathrm{a}}$

a Department of Chemistry and Biochemistry, The University of Texas at Dallas, 800 West Campbell Road, Richardson, Texas 75080, United States Contact: gassensmith@utdallas.edu

\begin{abstract}
Nanoparticle-based therapeutics have been applied in a broad range of clinical and pre-clinical applications from diagnosis to treatment for cancer. A wide range of synthetic and naturally occurring materials such as polymers, metal oxides, silicate, liposomes, and carbon nanotubes have been developed to overcome key barriers in small molecule therapeutics including intracellular trafficking, cell/tissue targeting, poor biodistribution, and low efficiency. Virus like particles (VLPs) — engineered and non-infectious self-assembling systems based on viral nanostructuresare new approach toward overcoming these limitations, as they are a protein-based nanomaterial that closely mimics the highly symmetrical and polyvalent conformation of viruses while lacking the viral genomes. Their innate biocompatibility, biodegradability, monodispersity, mild immunogenicity, and safety combined with the capacity to chemically modify the interior and exterior surfaces of these systems offer scientists a highly customizable tool to design and engineer multi-component therapeutic agents. In this review, we discuss how these systems have been used in a wide array of cancer treatments including phototherapy, immunotherapy, gene therapy, and chemotherapy.
\end{abstract}

Keywords: Virus-like particle, nanoparticle, cancer, phototherapy, immunotherapy, chemotherapy, gene therapy

\section{Introduction}

Over the last few decades, nanotechnology has been used increasingly in biomedicine, including applications for disease diagnosis and treatment [1, 2]. Tremendous effort has been devoted to designing a variety of organic and inorganic nanomaterials such as polymeric micelles [3], liposomes, dendrimers [4], carbon nanotubes [5], metal-organic frameworks [6, 7], and metal 
nanoparticles [8] to achieve safe and protected cargo for targeted delivery [9-11]. The appeal of these artificially engineered materials is based particularly on their versatile synthetic strategies, which give them physical and chemical properties such as shape, size, charge, surface patterning, biocompatibility, and the ability to selectively interact with distinct cells and tissues $[12,13]$. These properties allow them to resolve the main obstacles encountered with existing pharmaceutical treatments - poor bioavailability, rapid clearance, and uncontrollable release of drugs [14, 15]. However, despite advances, constructing simplistic and optimized synthetic nanostructures with low toxicity, multivalency, water solubility, functionalizability, and therapeutic loading capabilities, it challenging and complex process that limits the therapeutic application of these materials $[13,16,17]$. In the past three decades, biomolecule-based nanostructures - such as supramolecular self-assembled proteins, peptides, lipids, cellulose, and others - have paved a new way toward the design of sophisticated multimodal nanomaterials [17-19]. Supramolecular chemistry benefits from the nature of non-covalent interactions to integrate molecules such as proteins, small molecules, polysaccharides, and polymers in a dynamic and reversible state, which gives rise to multifunctional platforms with high sensitivity to bioenvironmental changes such as $\mathrm{pH}$, ionic strength, temperature, and oxidation [20-24]. This bottom-up approach elaborates upon structural and functional diversity, which offers suitable shapes, inner structure, organized architectures, and high biocompatibility and bioavailability. However, one key problem that these systems face is low biostability under physiological conditions, arising from the non-covalent linkage that hold the building blocks $[25,26]$. Therefore, there is an effort to identify systems that not only overcome design barriers associated with synthetic materials, but also provide the desired features of self-assembled nanostructures with integrated stability. Virus-like particles (VLPs) have attracted significant attention as self-assembled supramolecular systems that imitate the highly symmetrical, polyvalent, and monodisperse conformation of real viruses while lacking a viral genome (DNA or RNA), which render them noninfectious [27-29]. These proteinaceous materials offer advantages over the above-mentioned synthetic nanostructures by being biodegradable and biocompatible, as viruses are nature's tool to carry and deliver delicate genetic materials under adversarial physiological conditions [30, 31]. Many VLPs follow suit by being exceptionally stable and robust against harsh conditions such as high $\mathrm{pH}$ and temperature [10]. 


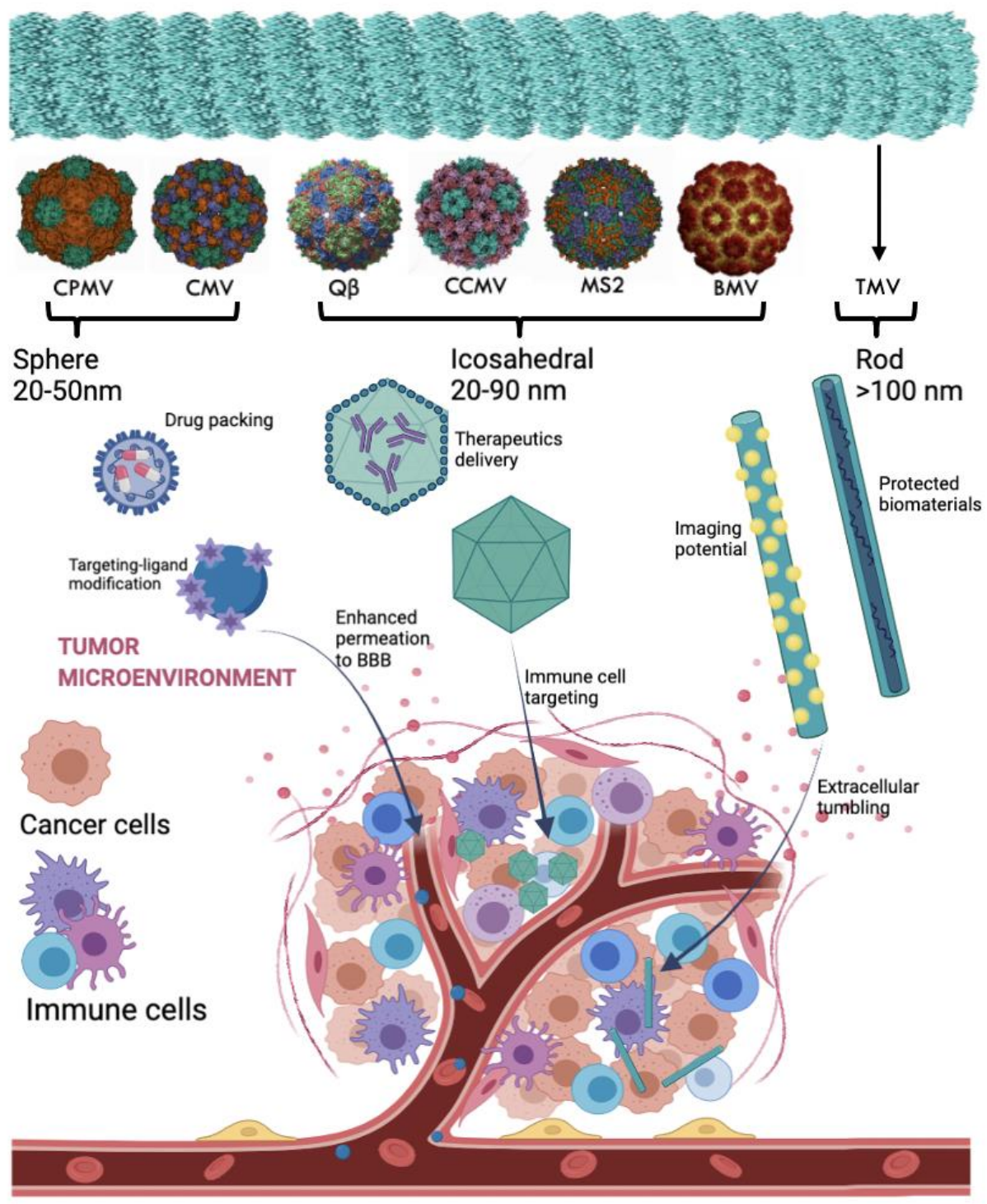

Figure 1. The structure function relationship of VLPs and their associated cellular uptake is innately related to their shape (noted by the arrows) while the chemical modification and loading capacities allow access to further targeted delivery of drugs, therapeutics, and biomaterials to specific cell types, such as cancer cells and immune cells, and regions, such as tumor microenvironments and passage to the blood brain barrier.

The synthesis and growth of VLPs has been reported in mammalian and insect cells [32, 33], bacteria, yeast [34], and transgenic plants [35]. With many regenerable sources like plants and bacteria, the harvesting of VLPs has ultimately led to the notion of VLP "farming" and large-scale production. The synthesis techniques for VLP generation have become quite sophisticated. Medicago, a Canada-based biotechnology company, has multiple plant-produced VLP-based 
vaccines under clinical investigation that are produced at a large scale [36]. The different sources of virus production result in the isolation of VLPs with different sizes (20-300 nm) and shapes (icosahedral, sphere, and rod) [37]. The variety of shapes and sizes afforded from VLPs allow different cellular interactions, uptake, and immune system activation in various biological environments e.g., tumor microenvironments, which provide various therapeutic applications such as imaging, immune cell targeting, and cargo delivery (Figure 1). For example, small-sized VLPs that range from 20-200 nm, are taken up by antigen presenting cells (APC) such as dendritic cells (DCs) and round VLP particles such as CCMV can reach secondary lymphoid organs better than rod like structures, resulting in a 100-fold increase in immune response in some cases [38]. However, even larger and rod-shaped viruses like the tobacco mosaic virus (TMV), have shown an order of magnitude increase in circulation time in the blood stream when coated with serum albumin, improving its therapeutic effect [39]. In all cases, the surface of these VLPs have a repetitive structure with solvent-exposed amino acids that allow for both genetic and chemical modification leading to a high density of functional groups. This unique and intrinsic feature of VLPs provides a large toolbox for chemists to construct bioconjugation schemes for adaptive functionality [40]. Many VLPs, including icosahedral Q $\beta$ and MS2, allow access to their interior cavity through their pores or disassembly/self-assembly processes can be utilized to create a reaction environment, load cargo, and/or provide a protective shield. For example, the plant-based viruses cowpea chlorotic mottle virus (CCMV), cucumber mosaic virus (CMV), and cowpea mosaic virus (CPMV) provide repeating functional handles for modification along both their interior and exterior surfaces for drug loading. The discrete "inner and outer" surfaces of VLPs provide a unique platform for concealing drug payloads within a VLP while modifying the outer surface for targeting. Therefore, VLPs offer a unique opportunity to combine benefits of the multiple surfaces and supramolecular self-assembly of liposomes with the polyvalency and robustness of polymers, while also coming in a variety of shapes and sizes that provide a unique versatility over most other materials [41]. They are so diverse that their innate substructures have therapeutic applications for a multitude of cancer treatment such as chemotherapy, phototherapy [42], immunotherapy [43] and combinations with imaging. All these unique abilities of VLP nanoparticles to self-assemble, and for multifaceted functionalization, biocompatibility, immunogenicity, and high stability, create an ideal material for designing many therapeutic agents [27, 37, 40]. 
In this review, we will discuss strategies involved in the surface modification, selective encapsulation of therapeutics, and exploitation of the versatility of VLPs to generate an effective cancer therapeutic platform in photothermal, immune, gene, and chemotherapies [44, 45].

\section{Surface Modification}

The intricate and repetitive design of virus-like particles allows for fabrication of highly tunable nanostructures for many therapeutic applications such as imaging, cancer therapy and drug delivery [46-48]. The high-density presentation of tumor antigens/epitopes [49], anti-cancer drugs [50], and targeting ligands [51] in a precise manner is possible by decorating the surface of VLPs using bioconjugation reactions. The surface of VLP capsids is typically populated with lysines [52], cysteines [53], and glutamic acids that allow for chemical attachment via bioconjugation for surface decoration with proteins, epitopes, antigens, and small molecules. Further, certain amino acids like methionine [54] can often be substituted for more nucleophilic or functionalizable amino acids by modifying the DNA used for capsid expression [55]. Active research in the field since the 1990s has helped develop an ever-expanding library of available chemical reactions that allow researchers to incorporate a larger repertoire of protein-VLP combinations to suit various cancer therapeutic needs.

Exploiting the already-present amino acids on the surface of a VLP is a very direct and effective approach for conjugation of various ligands, peptides, and small molecules for functionalization through several bioconjugation strategies (Figure 2). The VLPs CPMV, Q $\beta$, and MS2 have surface lysine groups that serve as reaction centers that can react through N-hydroxysuccinimide (NHS) ester chemistry for amide bond formation. This strategy is highly used for targeting many types of cancer cells known to overexpress folate receptors such as colorectal, ovarian, breast, and lung cancer. The decoration of drug carrying VLPs with a dense folic acid exterior promote targeting and efficiency of particle delivery, useful for delivering drugs like doxorubicin and cisplatin [56]. Destito et al. attached [57] a high density of folic acids (FA) — about 100 folic acid moieties on the surface of CPMV through the reaction of FA-NHS with solvent-exposed lysine groups to target cancer cells. Another example that further show cancer therapeutic applications of VLPs after lysine modification is reported by Aljabali et al.; in this work, the anticancer drug doxorubicin covalently attached [58] to the exterior of CPMV by EDC/NHS chemistry yields significant cytotoxicity to HeLa cells in vitro compared to free drug, owing to the concentrated presentation of drug into cancer cells. Cysteine groups on the VLP surface also offer a great platform for 


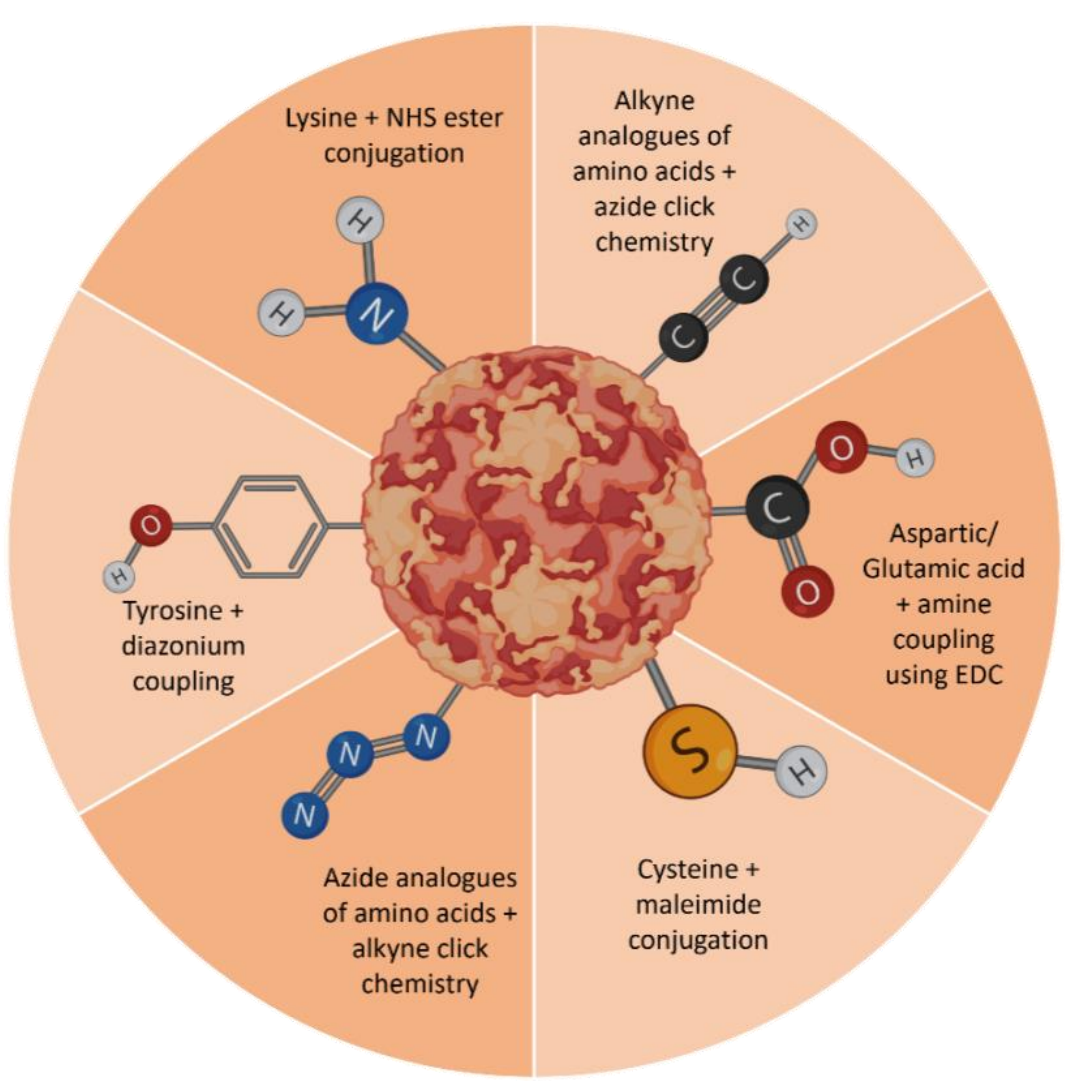

Figure 2: Common strategies employed for surface modification of VLPs associated with various natural and non-natural amino acid residues. The schematic represents an icosahedral VLP.

modification of various kinds, out of which the maleimide-thiol conjugations have been a popular approach and are hence extensively reported in literature.[59] However, free cystines are not common and instead are typically found as disulfide bonds, which are important for the structural stability of most proteins and VLPs [60, 61]. The more recent development of disulfide-bridging maleimides - first described [62] by Jones et. al. - has allowed for disulfides to be used as bioconjugation handles without losing the covalent character. For example, Chen et al. Synthesized [63] a library of dibromo maleimide derivatives and attached them by Michael addition to the 180 available cysteine residues on the surface of $\mathrm{Q} \beta$ (Figure 3A). The disulfide bridge first was reduced and then crosslinked with dibromo functionalized maleimides to from $\mathrm{Q} \beta$-maleimide conjugates. The developed modification was further used as a fluorescent probe for cell imaging.[64]

Strable et. al. demonstrated the $\mathrm{Cu}(\mathrm{I})$-catalyzed, azide-alkyne cycloaddition (CuAAC) strategy on Hepatitis B virus-like particle (HBV) and Q $\beta$ (Figure 3B) by conjugating 50\% of the azide positions available on the VLP surface with fluorescein alkyne dye [65, 66]. A very novel twist on 
click chemistry, which avoids the use of copper altogether, was demonstrated by Finbloom et. al. who showed [65] that cucurbit[6]uril (CB6) - traditionally used in rotaxane synthesis - could catalyze triazole formation between two modified proteins. They demonstrate this by first using an NHS ester to install azide groups onto TMV, followed by the addition of propargylamine in the presence of CB6 to form a triazole product (Figure 3C). This reaction exploits the aqueous environment by entropically driving the hydrophobic azide and alkyne into the inner cavity of CB6, which is further stabilized by the protonated amines. Confined inside the macrocycle, the alkyne and azide undergo a traditional Huisgen 1,3-dipolar cycloaddition.

When the natural surface of a VLP lacks available functional handles, amino acid analogues prove to be useful as they can be swapped out for their native amino acid, populating the exterior with suitable groups allowing further conjugation. For example, by optimizing the concentrations of tyrosine analogues like p-proparglycoxy-phenylalanine and p-azido-phenylalanine and methionine analogues like homopropargylglycine and azidohomoalanine respectively during protein expression, the native amino acid can be replaced by its analogue and providing the appropriate platform for suitable click chemistry conjugations [54]. Similar to the overexpression of folate receptors, prostate cancer cells are observed to have an overexpression of the membrane protease glutamate carboxypeptidase II (GPC II). Neburkova et. al. demonstrated [67] how click chemistry finds its application in prostate cancer therapeutics through conjugation of GPC II inhibitors onto several VLPs including Q $\beta$. Non-natural amino acids are often employed in the straightforward CuAAC strategy to achieve surface modifications of VLPs like Q $\beta$ and MS2 [54]. These residues are often azide or alkyne functionalized - or phosphines, but less popularly so - since they can undergo chemistry that works well in water and are orthogonal to bioconjugation strategies that depend on generating an electrophilic center.

A relatively newer approach for conjugation is chemoenzymatic strategies, where the coat proteins of the VLPs are genetically engineered to incorporate amino acids that can act as recognition sequences; these recognition sequences selectively bind with peptides to incorporate in a composite $[68,69]$. A special use case for this technique in therapeutic applications where the epitope/antigen to be delivered is a larger protein framework, and shorter peptide sequence derived from the antigen do not provide satisfactory amounts of antibody stimulation [70]. Several papers have used a sortase-mediated protein ligation strategies to achieve specific antigen binding [69, 70]. This ligation technique - also known as sortagging - employs the sortase enzymes present in the cell wall of gram-positive bacteria, which is known for its function of facilitating the anchoring of surface proteins with an LPTEG recognition sequence. The sortagging ability of 
bacteriophages is used to employ this enzymatic pathway for conjugating sequences of choice, that we can modify with an LPTEG sequence prior to the reaction [71].

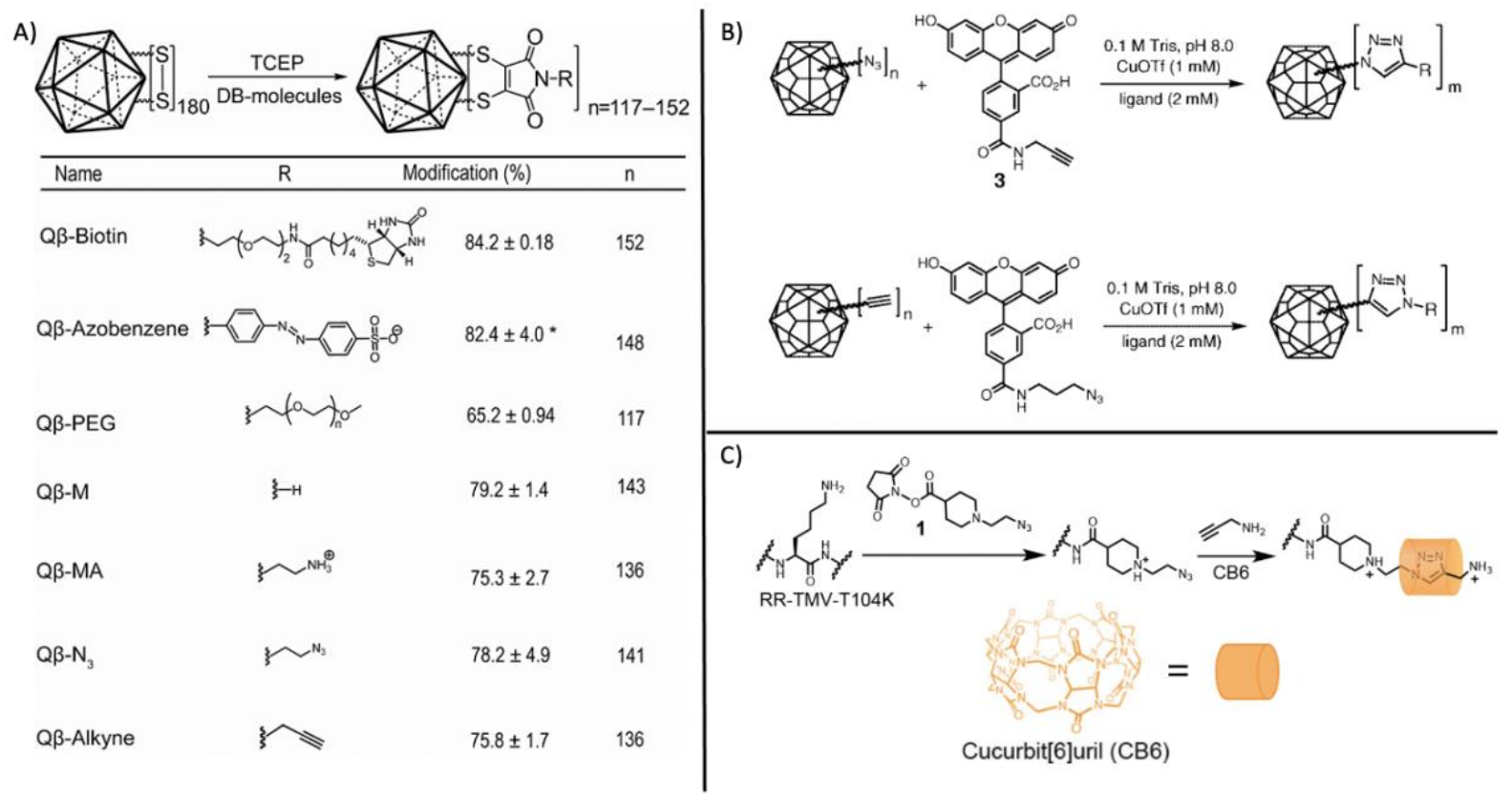

Figure 3. A) Reduction of disulfide bonds with TCEP and addition of dibromo maleimide to form maleimide conjugates demonstrated on icosahedral Q $\beta$ [63]. B) Cu-catalyzed azide-alkyne click chemistry demonstrated in fluorescein alkyne dye conjugation to icosahedral Q $\beta$ [66]. C) Functionalization of the rodlike VLP, TMV, with CB6 through reaction with formed triazole [65].

Addition of spacers to the VLP surface is a popular method for controlling the distance of attachment of peptides and epitopes to the surface, which can promote more efficient conjugation by eliminating steric congestion at the protein surface and allows more tunability in how dense the functionalization becomes. One end of these polar or non-polar flexible linkers are functionalized with azide or thiol groups depending on the chemistry required. Some of the more popular flexible linkers are found in the $-(\mathrm{Gly})_{\mathrm{n}}-\mathrm{Ser}-$ form and are known for providing an added flexibility to the structure [72]. J. Park et. al. showed [43] the use of GGGS linker to modify their peptide of choice with thiol and azide groups for conjugation via thiol-maleimide chemistry and azide-alkyne click chemistry respectively. Poly(ethylene)glycol (PEG) linkers are popular amongst several nanocarrier platforms for providing structural stability and improving circulation half-time [73]. PEGylation can help ensure the VLPs do not induce any unwanted immune responses and can promote extended circulation times. Bacteria-infecting viruses (phages), such as pseudo-spherical icosahedral structures $\mathrm{Q} \beta$ and MS2, can evade endosomal degradation through surface modification with ligands such as poly(lysine)-DNA complexes and SP94 peptides, which protect the VLP from unwanted biological activity $[74,75]$. 
VLPs allow for a high amount of precision in the practice of surface modification, giving one the ability to vary the epitope density on a virus-like particle by exercising control over the VLP-tocargo ratio in the coupling reactions [76]. Apart from that, the hollow structure of VLPs offer excellent control towards functionalizing the exterior and interior surfaces selectively using some of the aforementioned orthogonal reaction methodologies for dual modification [63, 77]. The advantages of using VLPs as a therapeutic platform are only further enhanced by their ability to be surface functionalized. We have discussed some popular approaches that have shown success in a variety of applications. With respect to cancer research, these surface functionalized VLPs serve as promising nanocarriers for non-invasive treatment strategies like phototherapy and immunotherapy. Their ability to deliver and present materials like chromophores and peptides is compounded by all the immunogenic benefits of using a non-synthetic biomaterial.

\section{Phototherapy}

Phototherapy, including photodynamic therapy (PDT) and photothermal therapy (PTT), has attracted extensive attention as a noninvasive, selective, and efficient cancer treatment strategy [78-80]. This method works based on interaction of light with chromophores that can then undergo different photochemical reactions or transformations to exert a therapeutic effect. PTT, which converts light into heat, utilizes the thermal sensitivity of cells to destroy tumors through converting light in the near infrared (NIR) region $(700-1100 \mathrm{~nm})$. The NIR spectrum has low absorption/scattering in biological systems from water and biomolecules like hemoglobin and melanin, giving it improved penetration depth through skin and tissues [81, 82]. To date, the most efficient converters of NIR radiation into heat have been inorganic materials including metal nanoparticles, carbon nanotubes, sulfide nanomaterials, and metal oxides; however there are concerns over possible term toxicity and slow or absent biodegradability. This pushes the need for organic molecules such as indocyanine green (ICG) and heptamethine dyes as alternative PTT materials. Organic-based PTT agents permit photophysical tunability, higher safety, and cell targeting abilities, thus improving photothermal conversion efficiency and photostability. In contrast to PTT, PDT converts light into reactive oxygen species (ROS), which are toxic to cells, by using the interaction of specific wavelength (within 600-800 nm) of light with a photosensitizer (PS) $[83,84]$. A photosensitizer at ground state $\left(\mathrm{S}_{0}\right)$ absorbs light energy and lifts an electron to an excited singlet state $\left(\mathrm{S}_{1}\right)$ where it undergoes an intersystem crossing by inverting the electron spin 
to the $\mathrm{T}_{1}$ state. While in a $\mathrm{T}_{1}$ state, the photosensitizer can abstract an electron from reducing molecules, such as tyrosine in a protein, to create a pair of radical anions $\left(\mathrm{PS}^{-} \cdot\right.$ ), which further donate their extra electrons to $\mathrm{O}_{2}$, producing superoxide anion radicals $\left(\mathrm{O}_{2}^{-}\right)$or other small molecule radicals to produce potentially toxic cell-damaging products. Alternatively, it can transfer its energy directly to molecular oxygen in triplet ground state $\left({ }^{3} \mathrm{O}_{2}\right)$, which converts ground state molecular oxygen into singlet oxygen $\left({ }^{1} \mathrm{O}_{2}\right)$, which readily undergoes irreversible addition to nucleic acids.

PTT and PDT not only kill irradiated tumor cells but can also stimulate a series of immune responses by releasing damage-associated molecular patterns (DAMPs) related to apoptotic or necrotic tumor cells and inflammatory cells $[85,86]$. VLPs have been used in phototherapy specifically PDT - for more than a decade. They have shown promising results thanks to their multivalency allowing them to carry photosensitizers/photo-absorbers along with cancer targeting moieties [87-89]. Generally, the efficiency of this strategy relies on the power of photoactive agents to trigger heat- or ROS-based cellular death, as well as initiating immunological cell death. One example of using VLPs to carry and locate high concentration of photosensitizer to the cells of interest for PDT is reported [90] by Rhee et al., where Q $\beta$ was modified with a metalloporphyrin derivative for PDT and a glycan ligand that can specifically target $\mathrm{CHO}-\mathrm{CD} 22$ receptor cells. The dual surface modification of $\mathrm{Q} \beta$ was performed through a $\mathrm{CuAAC}$ between azide-tailed zinc tetraaryl porphyrin (Figure 4A) ligand with alkyne-derivatized Q $\beta$ (Figure 4B). The functionality of VLP-mediated PDT was tested by treating CHO-CD22 cells with different concentrations of modified Q $\beta$, followed by exposure to radiation (Figure $\mathbf{4 C}$ ). The metabolic cell viability results showed modified Q $\beta$ construction could specifically kill CHO-CD22 cells through a dose dependent manner after photoactivation, whereas, cells incubated with unmodified $Q \beta$ remained viable after radiation. In addition, cytotoxicity was compared between CD22-positive and negative $\mathrm{CHO}$ cells after incubation with the same amount of conjugated $\mathrm{Q} \beta$ to show selectivity of attached ligands on cell surface receptors. Phase contrast and fluorescent microscope images show the selective nature of the modified $\mathrm{Q} \beta$ for $\mathrm{CHO}-\mathrm{CD} 22+$ cells by comparison to $\mathrm{CHO}-\mathrm{CD} 22-$ cells (Figure 4E). Therefore, VLPs offer great potential for targeted delivery of photosensitizing compounds and provide a promising scaffold for photodynamic cancer treatment that results in an improved therapeutic index. 

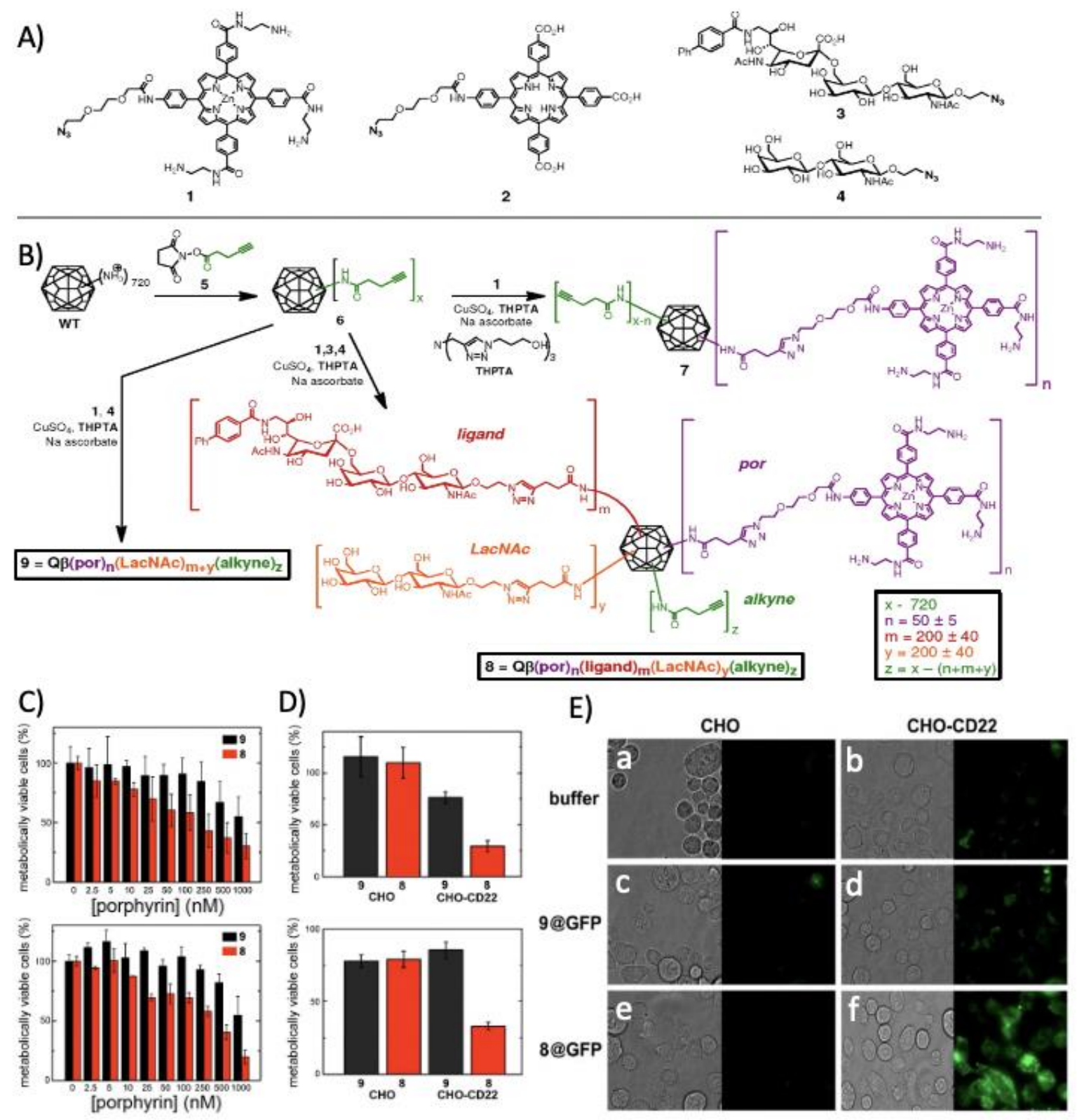

Figure 4. A) Azide-functionalized metalloporphyrin derivatives 1 and $\mathbf{2}$ and glycan ligands $\mathbf{3}$ and $\mathbf{4}$ for B) surface functionalization onto alkyne-modified Q $\beta$ VLPs through CuAAC. C) Dose-response phototoxicity induced by zinc porphyrin-loaded $\mathrm{Q} \beta$ particles on CHO-CD22 cells, under full-spectrum irradiation (IC50

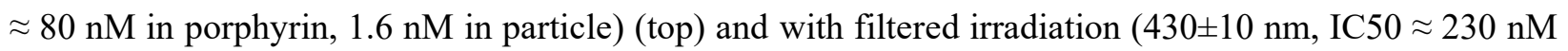
in porphyrin, $4.6 \mathrm{nM}$ in particle) (bottom). D) Comparison of CD22-negative and positive cells at $10 \mathrm{nM}$ particle concentration $(0.5 \mu \mathrm{M}$ in porphyrin), under full-spectrum irradiation (top) and with $50 \mathrm{nM}$ particles ( $2.5 \mu \mathrm{M}$ in porphyrin), under irradiation at $430 \pm 10 \mathrm{~nm}$ (bottom). The MTT assay was performed $24 \mathrm{~h}$ after light exposure. E) Phase contrast and fluorescent microscope images of $\mathrm{CHO}$ (a, c and e) and CHO-CD22+ cells (b, d and f) incubated with PBS (a and b), $9 @$ GFP16 (c and d), and 8@GFP16 (e and f) at $37{ }^{\circ} \mathrm{C}$ for 4 hours. Each particle was used at $1 \mathrm{nM}$ (50 nM in porphyrin); the @ symbol denotes the encapsulation of multiple copies of GFP inside the particle. Reproduced with permission from reference 90. 
A)

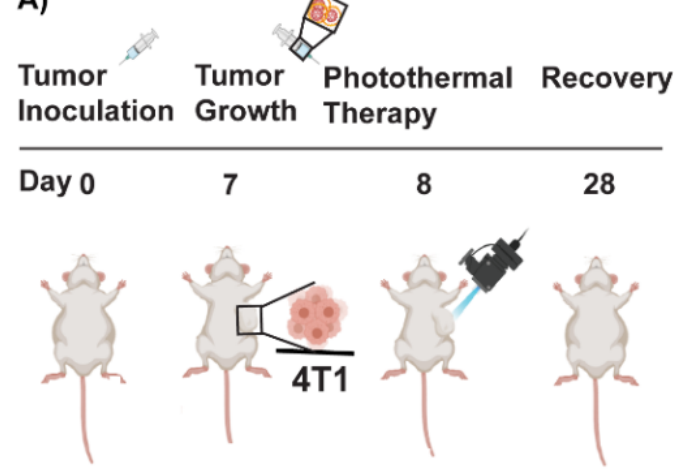

D)

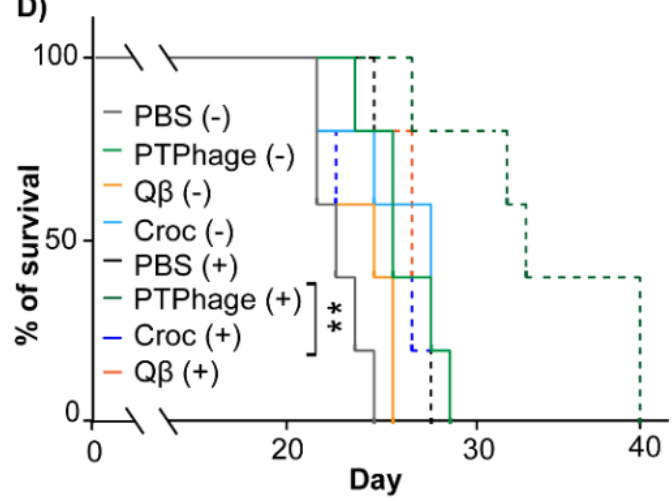

B)
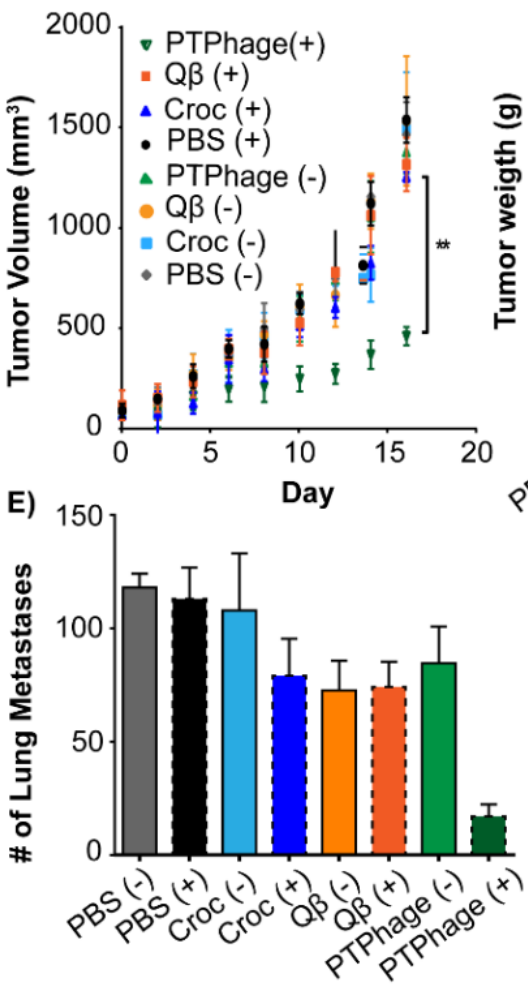

C)

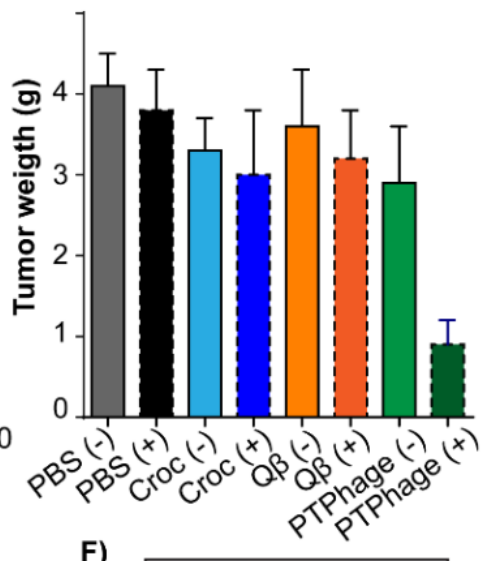

F)

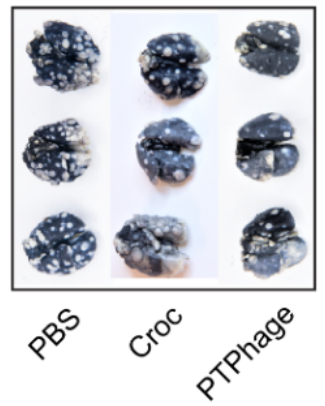

Figure 5: A) Experimental design of synergistic immunophotothermal therapy. B) Tumor growth curves of 4T1 tumor-bearing mice treated with PBS, Q $\beta$, Croc, and PTPhage with and without laser radiation showing the most effective therapeutic approach is attributed to PTPhage, which exhibited the greatest restriction to tumor growth. C) Tumor weight as a representation of tumor suppression verified high antitumor performance of PTPhage compared to Croc, Q $\beta$, and PBS groups. D) Survival study of 4T1 tumor-bearing BALB/c mice $(n=5)$. E) Number of lung nodules after India ink staining showed PTT modified VLP has significant effect in controlling metastasis. F) Representative images of India ink-infused lungs of irradiated Croc, PTPhage, and PBS mice with white spots clearly demonstrate number of metastatic nodules per each group. Reproduced with permission from reference 42 .

VLPs also offer great potential for displaying photo absorbers such as organic based NIR molecules on their exterior surface. High density of photoabsorbers on surface of VLPs along with their high thermal stability turn them to a highly stable and efficient photothermal agent more powerful than most common inorganic and organic PTT agents. More recently, Shahrivarkevishahi et al. designed [42] a photothermal and immunogenic VLP-based PTT agent called Photothermal 
Phage (PTPhage) through conjugation of hundreds of croconium dyes onto the solvent-exposed amine groups on the surface of $\mathrm{Q} \beta$ through EDC/NHS chemistry. The formulation showed significant enhancement in photothermal performance over free dye, and photothermal conversion efficiency, exceeding even gold nanorods. The cellular uptake and photothermal cy totoxicity of PTPhage was compared with free dye after incubating with identical concentrations of NIR dye with $4 \mathrm{~T} 1$ breast cancer cells. High cellular uptake and $48 \%$ more cellular toxicity after $808 \mathrm{~nm}$ laser radiation was observed for PTPhage compared to the free dye. The in vivo photothermal antitumor response was also assessed after treating 4T1 tumor-bearing female BALB/c mice with the VLP formulation. As shown in Figure 5, the PTT-mediated VLP showed significant tumor volume suppression, longer survival time, and significant prevention of lung metastases. The study further tested immunological responses triggered by the PTPhage as an immuno-photothermal combinational treatment compared to a monotherapy design (VLP and Free dye) where the data clearly proved higher activation of $\mathrm{CD}^{+}$and $\mathrm{CD}^{+} \mathrm{T}$ cells and dendritic cells, along with a significant reduction in immunosuppressive T-regulatory response. The implicit immunogenicity of $\mathrm{Q} \beta$ adds to the functionalization ability of VLPs and shows a great promise for designing highly effective immunotherapeutic agents that can promote therapeutic efficiency across the field of cancer immunotherapy.

\section{Immunotherapy}

Cancer immunotherapy works by stimulation of the immune system and is a strong method for inducing effective cellular and humoral immune responses, through vaccine and $\mathrm{T}$ cell infusion technologies, or through activating inhibitory antibodies on cancer cells [91, 92]. Virus like particles mimic the structure of viruses and their repetitive, highly-ordered antigenic structure can be recognized as a pathogen associated molecular patterns (PAMPs) by immune cells [93]. VLPs can directly interact with pathogen recognition receptors (PRRs), which are expressed on the cell surface and in endosomes of antigen presenting cells (APCs) - most notably dendritic cells (DCs) — and thus have been successfully used as adjuvants to elicit an immune response [94]. Activated DCs can process antigens into peptides for presenting on major histocompatibility complex class I/II (MHC-I/II) molecules that result in the creation of B7-1/CD80 and B7-2/CD86 costimulatory molecules and express pro-inflammatory cytokines that are necessary to prime the development of T cell and B cell immune responses [95]. The size distribution of VLPs is also within the optimal particle size range (20-200 $\mathrm{nm}$ ) allows for drainage to lymph nodes for distribution throughout the lymphatic system to initiate a robust immune response by interaction with different cell types in 
the secondary lymphoid organs $[94,96,97]$. Therefore, VLPs are able to induce T cell activation, which is related to antigen interaction of a T lymphocyte with APCs in secondary lymphatic tissue. T cells, including $\mathrm{CD} 8^{+}$cytotoxic $\mathrm{T}$ lymphocytes (CTLs) and $\mathrm{CD} 4^{+}$helper $\mathrm{T}$ cells, are key effector cells for anti-cancer immunity [98]. CTLs are able to kill tumor cells and activate APCs, following cytokine production, and creating a pro-inflammatory environment. CD4 ${ }^{+} \mathrm{T}$ cells, that are divided into different subtypes $\mathrm{T}_{\mathrm{H}} 1$ and $\mathrm{T}_{\mathrm{H}} 2$, induce cytokines that assist CTLs in killing tumor cells [99]. However, it is usually difficult to induce efficient CTL responses because of inefficient access of exogenous antigens to the MHC class I pathway [93, 100]. VLPs are capable of entering into both MHC I and MHC II presentation pathways and can therefore activate CD ${ }^{+} \mathrm{T}$ cells and direct them against cancer cells. VLPs with packed RNA during production can engage toll-like receptors (TLRs) including TLR7/8 and TLR3 and trigger innate immune responses [101]. While the ability of VLPs to produce a cellular response has been confirmed by several clinical and preclinical studies, the power to amplify and provoke a specific type of immune response shows how VLPs are a powerful and flexible platform that can be chemically or genetically functionalized with innate stimuli such as antigens and epitopes of interest. Decorating surface of VLPs with different ligands including peptides, proteins, nucleic acids, and small molecules have shown promising results for applications in cancer immunotherapy and developing cancer vaccines [102].

The main strategy for the presentation of these targeting moieties is through bioconjugation with exposed amino acid residues on VLPs, addressed by various chemistries such as click chemistry, NHS ester acylation, and coupling reactions [103]. One interesting example of using VLPs for cancer immunotherapies is conjugation of PD-1 peptide SNTSESF, known as AUR7, to the $30 \mathrm{~nm}$ icosahedral, plant-based CPMV [104]. It is reported that CPMV itself can be recognized by TLR2 and TLR4 to activate the innate immune system while the RNA inside CPMV can activate TLR7 $[105,106]$. As shown in Figure 6, a two-step bioconjugation strategy is used to couple the PD-1 peptide to CPMV, by first attaching a bi-functional (NHS)-PEG8-maleimide (SM-PEG8) linker to the lysine groups on the surface of CPMV through NHS-amine chemistry for amide formation. The second reaction is between the cysteine-terminated peptide and the maleimide on the linker, which resulted in the decoration of the surface of CPMV with 25 peptides. Therefore, the multivalent display and high concentration delivery of SNTSESF combined with the intrinsic immunogenicity of CPMV showed a promising synergistic effect in the treatment of mice bearing serous ovarian tumors. Data showed mice treated with several doses of peptide decorated CPMV had prolonged survival time significantly compared to free peptide and to a physical mixture of CPMV and peptide, demonstrating the enhanced effect of multivalent presentation combined with the immunogenicity of the formulation. Another example of using a VLP in cancer immunotherapy combined with their functionalizability was reported [107] by Wu et. al. They generated a library of 20 peptides of mucin-1 (MUC1), which is highly expressed by many types of cancer cells. The 
peptides were fused to the surface of $\mathrm{Q} \beta$ through an alkyl amide linker. They immunized mice with three different tumor models: B16 melanoma cells, MCF-7 breast cancer cells, and a metastasis model. Results showed the Q $\beta$-immunized mice had a significant reduction in the number of metastases in the lung.

A) linker

\section{SNTSESFGSGGGSGGC}

\section{anti-PD1 peptide conjugation handle}

B)

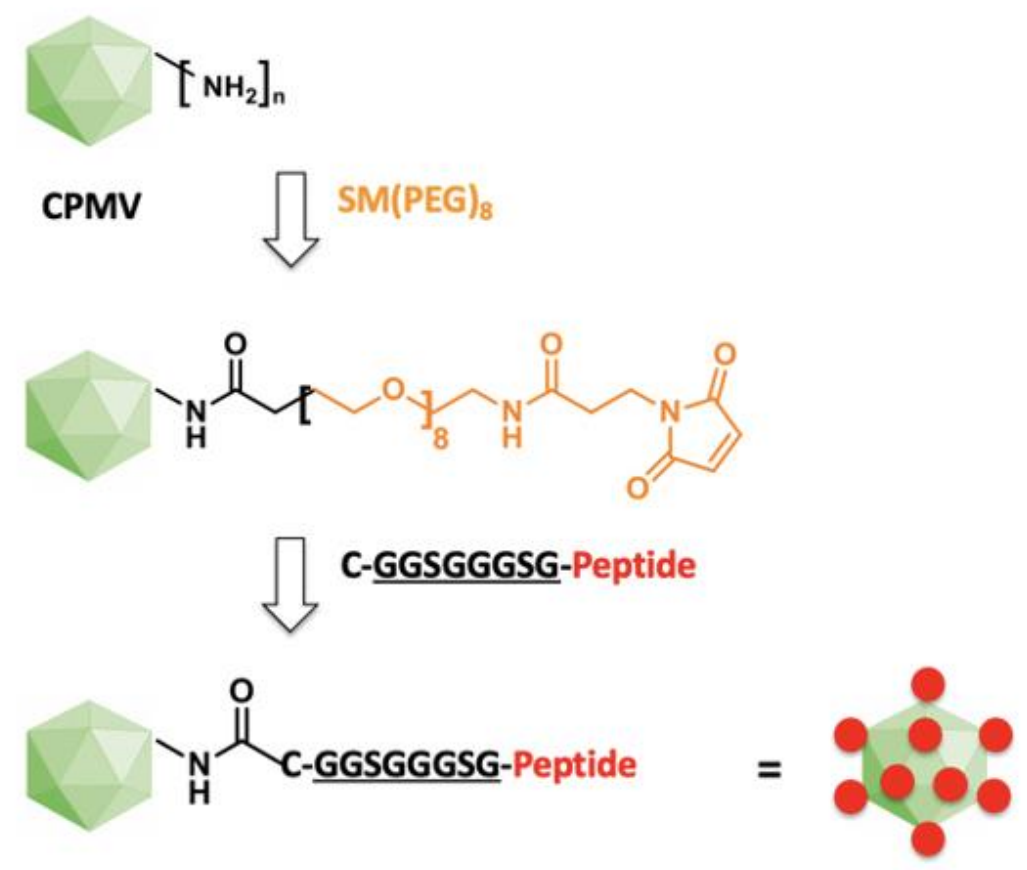

Figure 6: A) The amino acid sequence of the anti-PD-1 peptide SNTSESF with carboxy-terminal cysteine residue. B) Bioconjugation is formed first by attaching a bi-functional NHS-SM-PEG8 linker to a solvent-exposed amine group from lysine residues on CPMV, which provide maleimide groups for subsequent reaction with cysteine side chain of anti-PD1-peptides. Adapted from reference 110.

VLPs have also demonstrated increased humoral or antibody-mediated immunity by displaying foreign antigens on their surface. Humoral immunity begins with antigen engulfment by naïve B cells followed by transportation of the antigen to the lymph nodes. Through the production of cytokines, B cells differentiate into antibody secreting plasma cells, some of which are deemed as long-living plasma cells or memory B cells [108]. VLP-based humoral immunity such as cellular 
response is attributed to the size, repetitive geometric shape, and their TLR-agonizing ability. They are taken up by DCs or pass directly through lymphatic tissue, allowing for their downstream interaction with B cells. The highly ordered and repetitive structure of VLPs is recognized by B cell receptors (BCRs) and leads to a Th-dependent humoral immune response [93]. The use of a VLP as an epitope scaffold has shown to produce a higher antibody titer response. Literature has reported covalently attaching epitopes to the surface of VLPs can enhance antibody response significantly [109]. However, self-immunity — specifically in cases of cancer-related neoantigens - remains a large challenge in immunotherapy. The use of highly repetitive structure, which can be decorated with a multitude of neoantigens, overcomes the self-immunity associated with many previous vaccination strategies. For example, Palladini et al. demonstrated [110] with membrane protein HER-2 (Figure 6A) that is overexpressed in breast cancer cells, displayed on a VLP (Figure 6B) was able to induce a specific antibody response. The HER-2 VLP vaccination prophylactically reduced spontaneous tumor occurrence in HER-2 transgenic mice by 50-100\%. Also, the HER-2 VLP vaccination significantly reduced tumor growth and survival in wild-type mice injected with HER-2 expressing carcinoma.

VLPs, such as Q $\beta$ and MS2, are also often employed as cargo-loaded scaffolds for various immunological agents such as $\mathrm{CpG}$ or anti-cancer drugs, like doxorubicin, or modified with antigens/targeting linkers, such as macrolide antibiotics [111] for lung cancer targeting or peptide p33 [112] for melanoma tumor cells. The functional properties of VLPs can be further developed by not only antigens and targeting ligands but also encapsulating genetic materials, such as mRNA and siRNA. VLP capsids protect these materials from enzymatic degradation and detection by the body's immune system, resulting in sufficient delivery and therapeutic response [113].

\section{Encapsulation}

In addition to modifying the exterior surface of VLPs, the interior of icosahedral capsids can also be exploited for the delivery of various cargo. Three main methods exist for loading cargo into icosahedral VLPs. The first is to disassemble the VLP into its subunit proteins and reassemble the capsid in the presence of the cargo (Figure 7) [114-117]. During disassembly, the VLP is incubated with a chelating agent, such as egtazic acid (EGTA) or ethylenediaminetetraacetic acid (EDTA), to destabilize the capsid and a reducing agent, such as dithiothreitol (DTT), to break the disulfide bonds that bridge the pores. A denaturing agent, such as urea or glacial acetic acid, can also be used to help break down the capsid into individual coat proteins. This disassembly is done in a high salt solution to precipitate the RNA, which can be aided by the addition of nucleases and metal salts. The precipitated RNA is pelleted, and the coat protein solution is dialyzed and purified 
by size exclusion chromatography — usually Sephadex gel filtration — to remove excess salts and provide a pristine solution of VLP coat proteins. The coat proteins are then combined with the cargo of interest and dialyzed against a stabilizing high salt solution for reassembly. If needed, hydrogen peroxide can be added to help promote reformation of the disulfide bonds. It should be noted that the ratio of coat protein to cargo should be optimized to achieve maximal loading efficiency $[118,119]$.

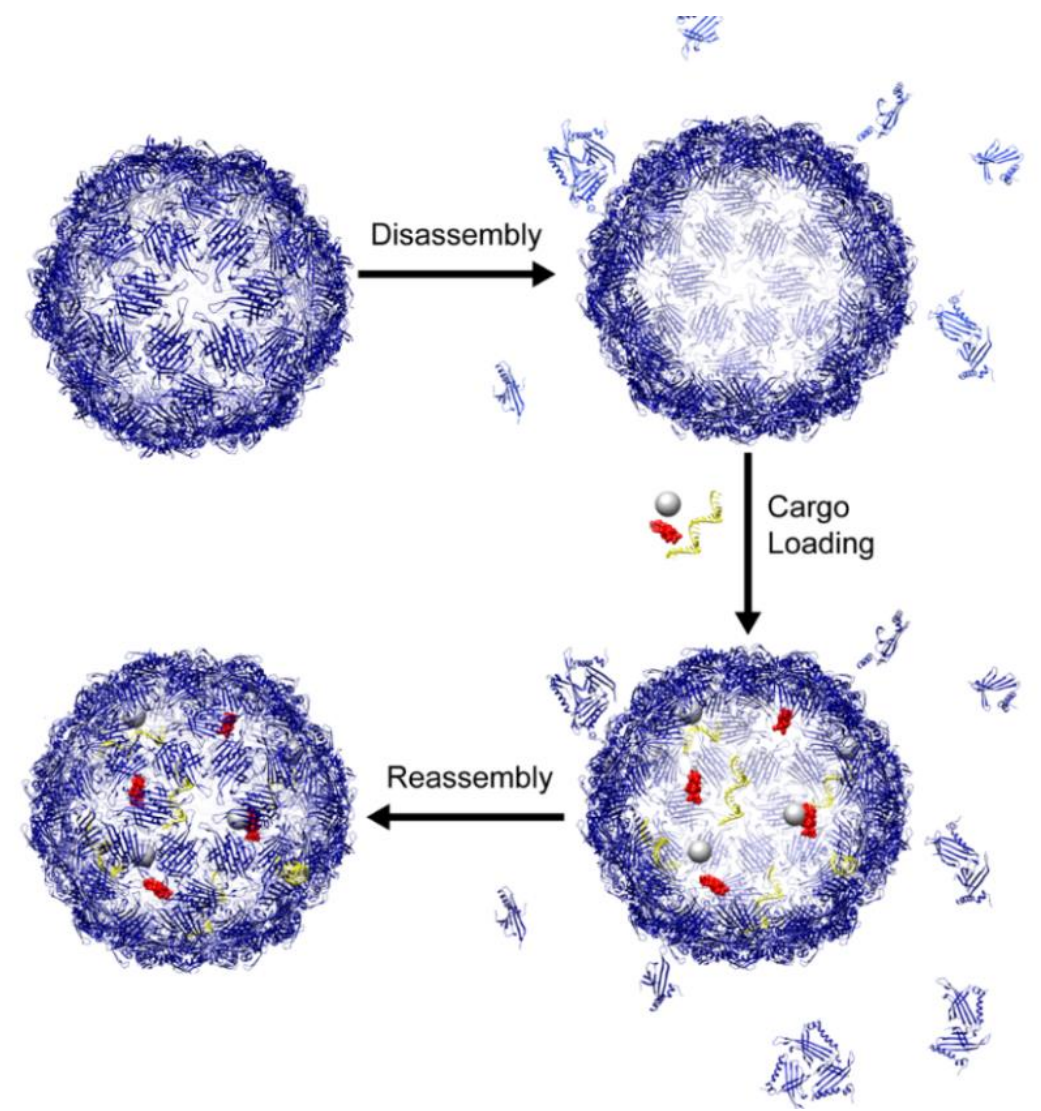

Figure 7: Encapsulation of cargo - e.g., protein, nucleic acid, and/or small molecules — into the interior of an icosahedral VLP via disassembly/reassembly method.

This method was inspired by the inherent action of VLPs to spontaneously assemble around nucleic acids and is driven by favorable interactions between coat protein-coat protein, coat protein-cargo, and cargo-cargo. Two proposed methods exist to detail the VLP assembly around a negatively charged cargo; (1) coat proteins assemble as a group in a disordered fashion and cooperatively arrange themselves to form an ordered capsid or (2) the coat protein-coat protein interactions are stabilized by the nucleic acid and instigate a nucleation growth mechanism with the sequential addition of coat proteins [120]. The preferred method of assembly is determined by the ionic strength of the solution; the former occurs primarily at low ionic strength whereas the 
latter occurs at higher ionic strength. Furthermore, individual coat proteins may electrostatically interact with an RNA motif that signals packaging of the viral genome during VLP expression [121-124]. Ashley et al. exploited [75] this trait by conjugating pac site RNA to quantum dots, drugs, and ricin toxin A-chain to mediate encapsulation of these cargo in the interior of the MS2 capsid during reassembly.

A second method to introduce cargo inside of a VLP — also possibly the simplest — is via diffusion through surface pores. VLPs often have small pores and if the cargo of interest is a small molecule, it can simply enter the interior of the capsid through these pores. For the icosahedral viruses, the surface pores are $\sim 2 \mathrm{~nm}$ in size [76]. Small molecules can diffuse into the interior of the capsid where they weakly bind to the charged coat protein or RNA, forming a low leakage drug carrier. For example, Franke et al. electrostatically immobilized the cationic anticancer drug (cisplatin) on the anionic inner surface of TMV [125]. Similarly, RNA-free capsids can be produced and then loaded with foreign genetic material via a "soaking" method that allows DNA to enter the interior of the capsid through the pores of the VLP, followed by binding of the stem loop to interior residues for oligodeoxynucleotide (ODN) retention [126]. In order to generate RNA-free capsids, the VLP is dialyzed against a high salt solution of physiological pH which causes the capsid to swell and become susceptible to nuclease action [127, 128]. Treatment with nucleases results in degradation of the RNA, and after purification by density gradient centrifugation, RNA-free VLPs are obtained [114].

The third method is to design a recombinant plasmid containing the coding sequence of the VLP coat protein, the mRNA sequence of interest, and the RNA motif sequence that binds the interior residues of the capsid. When this plasmid is expressed in a host system, the mRNA is encapsulated in the VLP during capsid formation by exploiting the interaction between the interior residues of the capsid and the RNA motif [129-134]. A dual plasmid expression system can be used if the promoters are compatible. This method has also been adapted to encapsulate proteins in the VLP

capsid during expression. Fielder et al. used [124] a dual plasmid expression system to co-express the VLP Q $\beta$ coat protein, a Rev-tagged cargo enzyme, and a bifunctional mRNA aptamer. The $\alpha$ Rev tagged aptamer binds to the Rev-tagged protein and the interior residues of the capsid through a hairpin loop resulting in enzyme encapsulation during in vivo assembly. These methodologies can be employed for the delivery of various cancer therapeutics including nucleic acids for gene therapy and small drug molecules for chemotherapy.

\section{Gene Therapy}

Gene therapy is a new technology being developed for the treatment of a wide variety of diseases, including cancer. This treatment method focuses on the delivery of foreign genetic material into 
cells to produce a therapeutic effect through the replacement or inactivation of a disease-causing gene [135]. For example, the p53 tumor suppressor gene that regulates cell division and cell death is mutated in over $50 \%$ of human cancers [136]. If this gene was replaced in cancer cells, the growth and spread of the cancer could be slowed. The first gene therapy product was actually a recombinant human p53 adenovirus for the treatment of head and neck cancer that was approved by the China Food and Drug Administration (CFDA) in 2003 and hit the market in 2004 [137]. In 2017, the first gene therapies were FDA approved and as of now, there are 20 FDA approved gene therapies, with thousands in clinical trials [138-140]. With this exploding technology, there is a significant amount of ongoing research dedicated to developing new and improved gene therapies.

The main obstacles facing gene therapies center around the fact that genetic material (DNA/RNA) is easily degraded by nucleases, is not targeted or efficiently taken up by cells, and can be degraded by lysosomes upon endocytosis [141, 142]. As a result, several methods have been developed to improve the efficiency of intracellular gene delivery including cell stressing (electroporation, heat shock), physical methods (injection, biolistic), nanoparticle-mediated delivery (liposomes, polymers, and nanoparticles), and viral vector delivery [143]. Of these methods, viral vector delivery is most commonly employed with adenovirus vectors used to deliver DNA and lentivirus vectors to deliver RNA [144]. However, these vectors lack a targeting mechanism and sometimes result in side effects $[145,146]$. As compared to other nanoparticle delivery systems, VLPs are more robust, biocompatible, monodisperse, and functionalizable and better suited for this task. Icosahedral VLPs (CCMV, MS2, and Q $\beta$ ) have been favored for gene therapy applications because of their small size $(\sim 28 \mathrm{~nm})$ as they can carry genetic material in their internal cavity, providing protection against nucleases. The positive surface charge of these VLPs means they can be readily taken up by cells and have the potential to shield the strong negative charge of the nucleic acid cargo. Furthermore, the surface of these VLPs can be functionalized with ligands for targeted delivery of genes to reduce off-target effects, and for endosomal escape to protect cargo from lysosomal degradation. The chemical modifiability of VLPs have made them strong candidates for gene delivery formulations with the means to overcome the current challenges facing the field today.

Each of the above methods have been used to efficiently encapsulate genetic cargo in VLPs for gene therapy [147], however dual plasmid [130] and disassembly/reassembly [119] are most commonly employed. For example, Lam et al. used [113] a disassembly/reassembly method (Figure 8A) to encapsulate siRNA targeting FOXA1 in the cowpea chlorotic mottle virus (CCMV) for the treatment of breast cancer. Initially it was found that the CCMV-siRNA was unable to silence the expression of FOXA1 in the breast cancer cell line MCF-7. However, after modifying 
A)
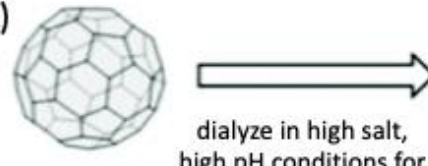

dialyze in high salt, high $\mathrm{pH}$ conditions for

$24 \mathrm{~h}$ to disassemble
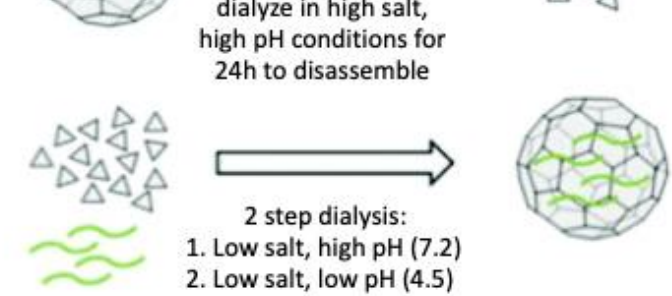

2. Low salt, low $\mathrm{pH}(4.5)$

C)
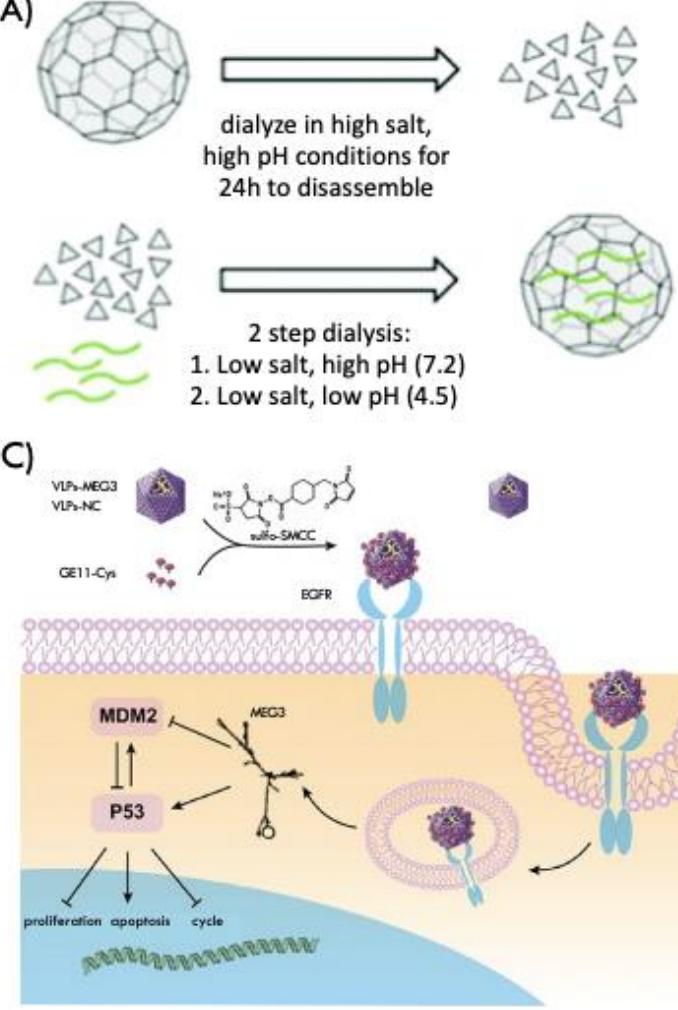

D)
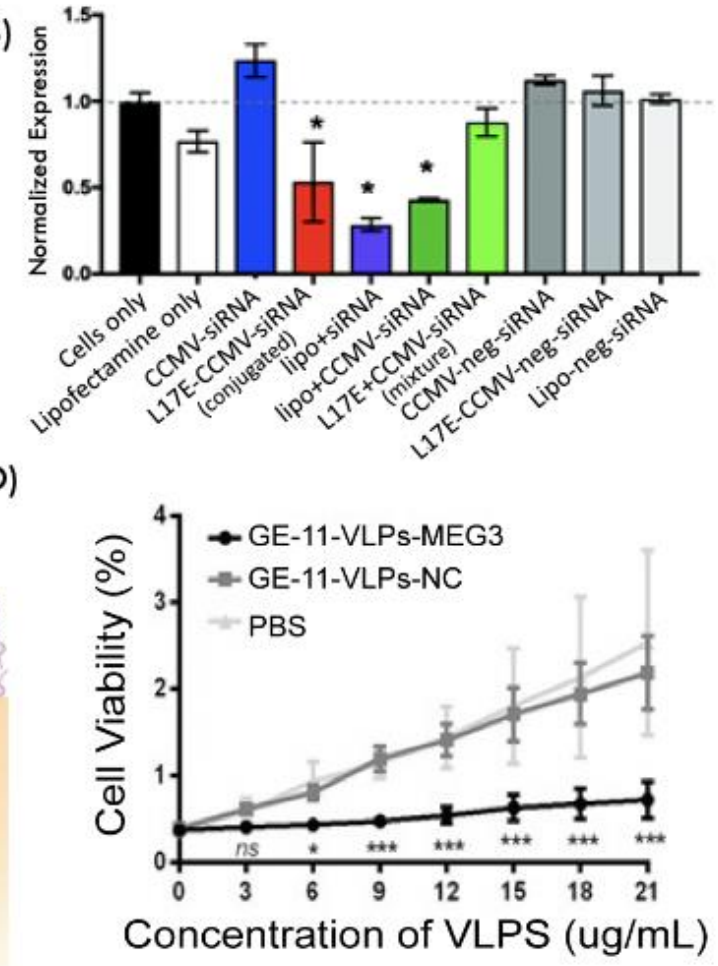

Figure 8. A) Disassembly of CCMV into coat proteins and subsequent reassembly in the presence of the siRNA to make CCMV-siRNA. B) FOXA1 expression levels in MCF-7 breast cancer cells following treatment with siRNA as determined by real time PCR. Reproduced with permission from reference 113. C) Encapsulation of MEG3 in MS2 by dual plasmid expression and subsequent modification with GE11 targeting peptide to make GE11-VLPs-MEG3. This formulation represses tumor growth by upregulating p53 expression and downregulating MDM2 expression. D) Proliferation of HepG2 hepatocellular carcinoma cells following treatment with GE11-VLPs-MEG3 as measured by CCK-8 viability assay. Reproduced with permission from reference 148.

the surface with the cell penetrating peptide, M-lycotoxin peptide L17E, the formulation was able to escape the endolysosomal compartment and achieve silencing that was comparable to lipofectamine delivery (Figure 8B). On the other hand, Chang et al. packaged [148] the long noncoding RNA tumor suppressor gene, maternally expressed gene 3 (MEG3), in MS2 via a dualplasmid expression system. After purifying the VLPs-MEG3, the surface was crosslinked with the dodecapeptide YHWYGYTPQNVI (GE11) to target the epidermal growth factor receptor (EGFR) that is overexpressed on many carcinoma cells (Figure 8C). With this targeted formulation, the authors were able to demonstrate hepatocellular carcinoma (HCC) tumor suppression in vitro and 
in vivo (Figure 8D). With the help of VLPs, researchers have been able to overcome the main challenges facing gene therapy today by providing a multivalent system that can both protect genetic cargo from nuclease degradation and offer targeted, efficient delivery. In addition to encapsulating genetic materials, VLPs can carry a high dose of various anti-cancer drugs and improve chemotherapy treatments by targeting delivery to cancer cells and minimizing the side effects on healthy cells.

\section{Chemotherapy}

Chemotherapy is the most common anti-cancer treatment. Chemotherapeutic agents are small molecules that kill and inhibit the growth and spread of cancer cells, typically by targeting fast growing cells. Common therapeutic agents such as doxorubicin, cisplatin, and 5-fluorouracil tend to be broadly cytotoxic, and when introduced systemically, they cause harsh side effects [149]. The use of chemotherapeutics to effectively fight cancer while minimizing the systemic side effects remains an issue in anti-cancer research [150]. The use of nanocarriers such as VLPs is one way to effectively target tumors while minimizing toxicity in healthy tissues [151]. Some advantages of VLPs over traditional nanoparticles as drug vehicles include their biocompatible and biodegradable nature, straight-forward production, and enhanced cellular uptake [152]. Importantly, the ability of VLPs to effectively deliver therapeutic agents is attributed to the enhanced endocytic uptake of the capsid over the free drug. Once endocytosed and trafficked into the lysosome, the capsid is degraded, releasing the anti-cancer drug.

As previously discussed, there are multiple methods to encapsulate cargo inside VLPs. VLPs possess a natural affinity for encapsulating anionic moieties, which mimic their native viral genome, making them well-suited for RNA delivery [153-155]. Similarly, encapsulation of therapeutics can be achieved through the denaturation of the coat protein followed by the renaturation of the capsid around the negative charge of new cargo or by taking advantage of the RNA stem loop (pac site) that mediates coat protein self-assembly [121, 130]. Many VLP capsids are porous in nature to protect their encapsulated genome while allowing the diffusion of water and ions. These porous capsids allow for the infusion or diffusion of small molecules such as chemotherapeutic agents across the VLP [156]. Yildiz et al. loaded [157] CPMV with proflavine by utilizing the affinity of the drug towards the interior, negatively charged RNA. It was demonstrated the CPMV lacking RNA was not able to load the drug cargo. This method resulted in anti-cancer activity across several cancer cell lines. Introducing "smart" behavior into VLPs to control drug release has also been developed. Benjamin et al. loaded [89] doxorubicin noncovalently into Qß through infusion of the drug. Doxorubicin — which is positively charged and hydrophobic - weakly binds to the single-stranded RNA inside Qß. Following drug loading, 
photolytically active gold nanoparticles were grown onto the pores, guided by disulfide residues, effectively capping the pores of the VLP (Figure 9A). Using nanosecond laser irradiation, the group was able to target drug release in specific locations resulting in cell death. Upon irradiation, AuNPs converted the light energy to heat, causing the breakdown of the capsid. Doxorubicin was then released from the capsid and shows cytotoxic effects in cells only in the laser pathway. This specificity is attributed to the nanosecond irradiation, which prevented the heating of the bulk of the solution. Upon incubation alone, AuNP@Q $\beta$ (Dox) showed high cell viability after $4 \mathrm{~h}$ incubation with RAW macrophages, whereas free Dox showed a significantly lower cell viability (Figure 9B). The in vitro release of Dox in A549 lung cancer cells was observed only after irradiation, as demonstrated below through live cell fluorescent imaging (Figure 9C-E).
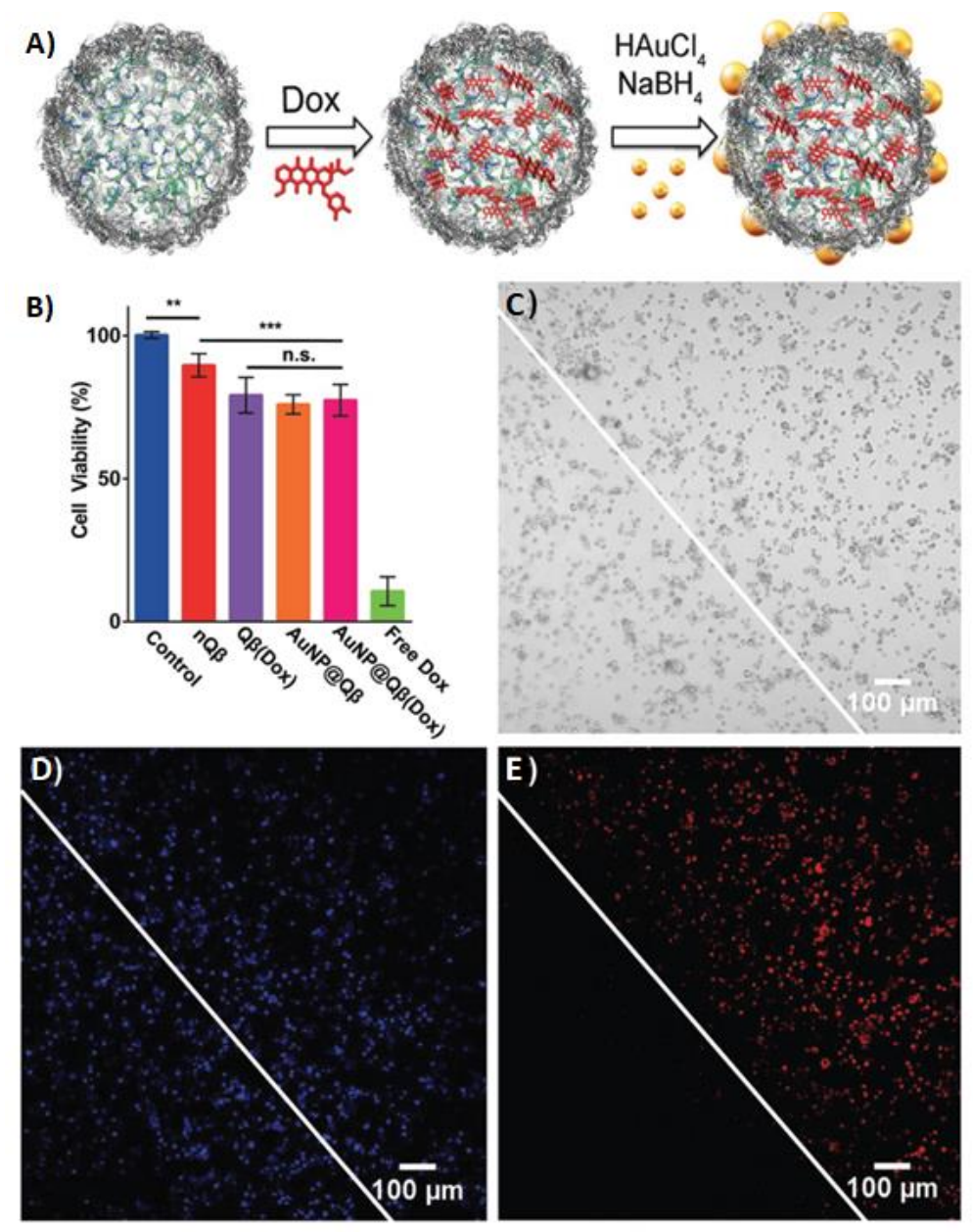

Figure 9. $\mathrm{A}) \mathrm{Q} \beta$ possesses 32 pores $(1.5$ or $3.0 \mathrm{~nm}$ ) allowing for the diffusion of doxorubicin in or out of the VLP. Pores are then capped with $6 \mathrm{~nm}$ AuNPs. B) Cytotoxicity analysis after $4 \mathrm{~h}$ incubation of AuNP@Q $\beta$ nanoparticle composites. C-E) Wide-field live cell images depicting Dox release post irradiation, right side depicts laser treated: C) bright-field, D) nuclear stain, Hoechst 34442 nuclear dye, and E) doxorubicin (excitation $470 \mathrm{~nm}$, emission $560 \mathrm{~nm}$ ). Reproduced with permission from reference 89. 


\section{Conclusion}

Virus-like particles are self-assembled from viral structural proteins with incredibly organized scaffolds. These biocompatible and nontoxic particles are widely used in nanomedicine and show special promise for cancer therapies. Their capabilities to be modified genetically and chemically on their outer surface and inner cavities through amino acid chemistries and self-assembly processes offer specific targeting, stability, and solubility. They are considered not only as excellent packaging and delivery tools for anti-cancer drugs and genetic materials, but also a powerful platform to display antigens, epitopes, PT agents, surfactants, polymer coatings, and ligands in a dense repeating array to improve therapeutic efficiency. Moreover, VLPs can engage both the innate and adaptive immune systems even without any adjuvants in a similar way to pathogens. These smart multifunctional nanocarriers can act as potential combinational therapeutics with existing strategies such as phototherapy, immunotherapy, gene therapy, and chemotherapy. The success of these protein-based nanoparticles with well-designed structures offer a more powerful toolbox for clinical cancer treatment in the near future.

\section{Funding}

J.J.G. acknowledges National Science Foundation (Grants CAREER DMR-1654405 and DMR2003534) and the Welch Foundation (Grant AT-1989-20190330). N.J.D. acknowledges the Welch Foundation (Grant AT-2030-20200401).

\section{References}

[1] R. Rezaei, M. Safaei, H.R. Mozaffari, H. Moradpoor, S. Karami, A. Golshah, B. Salimi, and H. Karami, The Role of Nanomaterials in the Treatment of Diseases and Their Effects on the Immune System. Open Access Maced J Med Sci. 7 (2019) 1884-1890. https://doi.org/10.3889/oamjms.2019.486.

[2] M. Patil, D.S. Mehta, S. Guvva, Future impact of nanotechnology on medicine and dentistry. J Indian Soc Periodontol. 12 (2008) 34-40. https://doi.org/10.4103/0972-124X.44088

[3] J. Gong, M. Chen, Y. Zheng, S. Wang, Y. Wang, Polymeric micelles drug delivery system in oncology. Journal of Controlled Release, 159 (2012) 312-323.

https://doi.org/10.1016/j.jconrel.2011.12.012

[4] P.E. Roopngam, Liposome and polymer-based nanomaterials for vaccine applications.

Nanomedicine Journal. 6 (2019) 1-10. https://doi.org/10.22038/NMJ.2018.06.001

[5] G. G. Wildgoose, C. E. Banks., R. G. Compton, Metal Nanoparticles and Related Materials

Supported on Carbon Nanotubes: Methods and Applications. Small 2 (2006) 182-193.

https://doi.org/10.1002/smll.200500324 
[6] M. Wu and Y. Yang, Metal-Organic Framework (MOF)-Based Drug/Cargo Delivery and Cancer Therapy. Advanced Materials 29 (2017). https://doi.org/10.1002/adma.201606134

[7] Y. Sun, L. Zheng, Y. Yang, X. Qian, T. Fu, X. Li, Z. Yang, H. Yan, C. Cui, W. Tan, MetalOrganic Framework Nanocarriers for Drug Delivery in Biomedical Applications. Nano-Micro Lett. 12 (2020). https://doi.org/10.1007/s40820-020-00423-3

[8] M.T. Iqbal, K. Halasz, D. Bhatia, Metallic Nanoparticles for Targeted Drug Delivery.

Nanomat. Che Tech 1, (2017)

[9] R. Misra, S. Acharya, S.K. Sahoo, Cancer nanotechnology: application of nanotechnology in cancer therapy. Drug Discovery Today 15 (2010) 842-850.

https://doi.org/10.1016/j.drudis.2010.08.006

[10] H. Choi, W. Liu, F. Liu, K, Nasr, P. Misra, M.G. Bawendi, J.V Frangioni, Design considerations for tumour-targeted nanoparticles. Nature Nanotech 5 (2010) 42-47. https://doi.org/10.1038/nnano.2009.314

[11] F. ud Din, W. Aman, I. Ullah, O. S. Qureshi, O. Mustapha, S. Shafique, A. Zeb, Effective use of nanocarriers as drug delivery systems for the treatment of selected tumors. Int $\mathbf{J}$

Nanomedicine 12 (2017) 7291-7309. https://doi.org/10.2147/IJN.S146315

[12] I. Khana, K. Saeed, I. Khan, Nanoparticles: Properties, applications and toxicities. Arabian Journal of Chemistry 12 (2019) 908-931. https://doi.org/10.1016/j.arabjc.2017.05.011

[13] J.K. Patra, G. Das, L.F. Fraceto, E.V. Ramos Campos, M. P. Rodriguez-Torres, L. S.

Acosta-Torres, L.A. Diaz-Torres, R. Grillo, M. K. Swamy, S. Sharma, S. Habtemariam, H. Shin, Nano based drug delivery systems: recent developments and future prospects. J

Nanobiotechnology 16 (2018). https://doi.org/10.1186/s12951-018-0392-8

[14] N. Scotti, E.P. Rybicki, Virus-like particles produced in plants as potential vaccines. Expert Rev Vaccines.12 (2013) 211-24. https://doi.org/10.1586/erv.12.147

[15] S. Chen, Q. Zhang, Y. Hou, J. Zhang, X. Liang, Nanomaterials in medicine and pharmaceuticals: nanoscale materials developed with less toxicity and more efficacy. European Journal of Nanomedicine 5 (2013) 61-79. https://doi.org/10.1515/ejnm-2013-0003 [16] R.Song, M. Murphy, C. Li, K. Ting, C. Soo, Z. Zheng, Current development of biodegradable polymeric materials for biomedical applications. Drug Des Devel Ther. 12 (2018) 3117-3145. https://doi.org/10.2147/DDDT.S165440

[17] Y. Santosh, S.A Kumar, K. Pradeep, Nanoscale Self-Assembly for Therapeutic Delivery. Front. Bioeng. Biotechnol. 8 (2020) 127. https://doi.org/10.3389/fbioe.2020.00127

[18] Y. Lin, C. Mao, Bio-inspired supramolecular self-assembly towards soft nanomaterials. Front Mater Sci. 5 (2011) 247-265. https://doi.org/10.1007/s11706-011-0141-5

[19] N. Habibi, N. Kamaly, A. Memic, H. Shafiee, Self-assembled peptide-based nanostructures: Smart nanomaterials toward targeted drug delivery. Nano Today 11 (2016) 41-60. https://doi.org/10.1016/j.nantod.2016.02.004

[20] R. Lu, X. Zhang, X. Cheng, Y. Zhang, X. Zan, L. Zhang, Medical Applications Based on Supramolecular Self-Assembled Materials From Tannic Acid. Front Chem. 8 (2020) 583484. https://doi.org/10.3389/fchem.2020.583484

[21] M. Malkoch, E. Malmström Jonsson, A.M. Nyström, Dendrimers: Properties and Applications, in K. Matyjaszewski, M. Möller, (Eds), Polymer Science: A Comprehensive Reference, 10 Volume Set, Elsevier, 2012, pp 113-176. https://doi.org/10.1016/B978-0-44453349-4.00162-X

[22] M. J. Webber, E. A. Appel, E. W. Meijer, R. Langer, Supramolecular biomaterials. Nature materials, 15 (2016) 13-26. https://doi.org/10.1038/nmat4474 
[23] M.C. T. Fyfe, J. F. Stoddart. Synthetic Supramolecular Chemistry. Acc. Chem. Res. 30 (1997) 393-401. https://doi.org/10.1021/ar950199y

[24] J.D. Badjić, A. Nelson, S. J. Cantrill, W. B. Turnbull, J.F. Stoddart, Multivalency and

Cooperativity in Supramolecular Chemistry. Acc. Chem. Res. 38 (2005) 723-732.

https://doi.org/10.1021/ar040223k

[25] X. Jin, L. Zhu, B. Xue, X. Zhu,D. Yan, Supramolecular nanoscale drug-delivery system with ordered structure. National Science Review 6 (2019) 1128-1137.

https://doi.org/10.1093/nsr/nwz018

[26] J. Zhou, J. Li, X. Du, B. Xu, Supramolecular biofunctional materials. Biomaterials 129

(2017)1-27. https://doi.org/10.1016/j.biomaterials.2017.03.014

[27] X. Ding, D. Liu, G. Booth, W. Gao, Y. Lu, Virus-Like Particle Engineering: From Rational Design to Versatile Applications. Biotechnol. J. 13 (2018).

https://doi.org/10.1002/biot.201700324

[28] B. Schwarz, M. Uchida, T. Douglas, Biomedical and Catalytic Opportunities of Virus-Like Particles in Nanotechnology. Adv Virus Res. 97 (2017) 1-60.

https://doi.org/10.1016/bs.aivir.2016.09.002

[29] B. Donaldson, F Al-Barwani, V. Young, S. Scullion, V Ward, S. Young, Virus-like

particles, a versatile subunit vaccine platform. Subunit Vaccine Delivery. Berlin: Springer 2015,

p. 159-80. https://doi.org/10.1007/978-1-4939-1417-3_9

[30] P. Pushko, P. Pumpens, E. Grens, Development of Virus-Like Particle Technology from

Small Highly Symmetric to Large Complex Virus-Like Particle Structures. Intervirology 56

(2013) 141-165. https://doi.org/10.1159/000346773

[31] M. A. Luzuriaga, R. P. Welch, M. Dharmarwardana, C. E. Benjamin, S. Li, A.

Shahrivarkevishahi, S. Popal, L. H. Tuong, C. T. Creswell, J. J. Gassensmith, Enhanced Stability and Controlled Delivery of MOF-Encapsulated Vaccines and Their Immunogenic Response In Vivo. ACS Appl. Mater. Interfaces 11 (2019) 9740-9746.

https://doi.org/10.1021/acsami.8b20504

[32] L. Cervera, A. A. Kamen, Large-Scale Transient Transfection of Suspension Mammalian

Cells for VLP Production. Methods Mol Biol. 1674 (2018) 117-127. https://doi.org/10.1007/9781-4939-7312-5_10

[33] G. Dong-hang, C. Chen, C. Lin, H. Chen, H. Chen, Improvement of glycosylation in insect cells with mammalian glycosyltransferases. J Biotechnol. 102 (2003) 61-71.

https://doi.org/10.1016/s0168-1656(02)00364-4

[34] A. Schneemann, M. J. Young, Viral Assembly Using Heterologous Expression Systems and Cell Extracts. Advances in Protein Chemistry 64 (2003) 1036. https://doi.org/10.1016/s00653233(03)01001-5

[35] E.P. Rybicki, Plant molecular farming of virus-like nanoparticles as vaccines and reagents. WIREs Nanomed Nanobiotechnol. 12 (2020) 1587. https://doi.org/10.1002/wnan.1587

[36] M. A. D'Aoust, M. M. Couture, N. Charland, S. Trépanier, N. Landry, F. Ors, L. P. Vézina, The production of hemagglutinin-based virus-like particles in plants: a rapid, efficient and safe response to pandemic influenza. Plant Biotechnology 8 (2010) 607-619.

https://doi.org/10.1111/j.1467-7652.2009.00496.x

[37] D. Diaz, A. Care, A. Sunna, Bioengineering Strategies for Protein-Based Nanoparticles. Genes (Basel) 9 (2018) 370. https://doi.org/10.3390/genes9070370

[38] S. Zinkhan, A. Ogrina, I. Balke, G. Reseviča, A. Zeltins, S. de Brot, C. Lipp, X. Chang, L. Zha, M. Vogel, M. F. Bachmann, M. O. Mohsen, The impact of size on particle drainage 
dynamics and antibody response. Journal of Controlled Release 331 (2021) 296-308.

https://doi.org/10.1016/j.jconrel.2021.01.012

[39] A.S. Pitek, S. A. Jameson, F.A. Veliz, S. Shukla, N. F. Steinmetz, Serum albumin

'camouflage' of plant virus based nanoparticles prevents their antibody recognition and enhances pharmacokinetics. Biomaterials 89 (2016) 89-97.

https://doi.org/10.1016/j.biomaterials.2016.02.032

[40] H.E. van Kan-Davelaar, J.C. van Hest, J.J. Cornelissen, M. S. Koay, Using viruses as nanomedicines. Br J Pharmocol. 171 (2014) 4001-4009. https://doi.org/10.1111/bph.12662 [41] D.T. Le, K.M. Müller, In Vitro Assembly of Virus-Like Particles and Their Applications. Life 11 (2021) 334. https://doi.org/10.3390/life11040334

[42] A. Shahrivarkevishahi, M. A. Luzuriaga, F. C. Herbert, A. C. Tumac, O. R. Brohlin, Y. H. Wijesundara, A. V. Adlooru, C.Benjamin, H. Lee, P. Parsamian, J. Gadhvi, N. J. De Nisco, J. J. Gassensmith, PhotothermalPhage: A Virus-Based Photothermal Therapeutic Agent. J. Am. Chem. Soc. 143 (2021) 16428-16438. https://doi.org/10.1021/jacs.1c05090

[43] Y. H. Chung, J. Park, H. Cai, N. F. Steinmetz, S100A9-Targeted Cowpea Mosaic Virus as a Prophylactic and Therapeutic Immunotherapy against Metastatic Breast Cancer and Melanoma. Adv. Sci. (Weinh) 21 (2021) e2102796. https://doi.org/10.1002/advs.202101796 [44] Y. H. Chung, H. Cai, N. F. Steinmetz, Viral nanoparticles for drug delivery, imaging, immunotherapy, and theranostic applications. Advanced Drug Delivery Reviews 156 (2020) 214-335. https://doi.org/10.1016/j.addr.2020.06.024

[45] J. K. Pokorski, N. F. Steinmetz, The art of engineering viral nanoparticles. Mol Pharm. 8 (2011) 29-43. https://doi.org/10.1021/mp100225y

[46] S. Nooraei, H. Bahrulolum, Z. S. Hoseini, C. Katalani, A. Hajizade, A.J. Easton, G. Ahmadian, Virus-like Particles: preparation, immunogenicity and their roles as nanovaccines and drug carriers. Journal of Nanobiotechnology 19 (2021) 59. https://doi.org/10.1186/s12951-02100806-7

[47] A. Roldão, M. C. Mellado, L. R. Castilho, M. J. Carrondo, P. M. Alves, Virus-like particles in vaccine development. Expert Rev Vaccines. 9 (2010) 1149-1176.

https://doi.org/10.1586/erv.10.115

[48] I. J. Hildebrandt, S. S. Gambhir, Molecular imaging applications for immunology. Clin Immunol. 111 (2004) 210-24. https://doi.org/10.1016/j.clim.2003.12.018

[49] B. Donaldson, F. Al-Barwani, S.J. Pelham SJ, K. Young, V. K. Ward, S. L. Young, Multitarget chimaeric VLP as a therapeutic vaccine in a model of colorectal cancer. Journal for ImmunoTherapy of Cancer 5 (2017) 69. https://doi.org/10.1186/s40425-017-0270-1

[50] E. J. Hartzell, R. M. Lieser, M. O. Sullivan, W. Chen, Modular Hepatitis B Virus-like Particle Platform for Biosensing and Drug Delivery. ACS Nano 14 (2020) 12642-122651. https://doi.org/10.1021/acsnano.9b08756

[51] C.C. Chen, L. Xing, M. Stark, T. Ou, P. Holla, K. Xiao, S. G. Kamita, B. D. Hammock, K. Lam, R. H. Cheng, Chemically activatable viral capsid functionalized for cancer targeting. Nanomedicine 11 (2016) 377-390. https://doi.org/10.2217/nnm.15.207 [52] P. Singh, G. Destito, A. Schneemann, M. Manchester, Canine parvovirus-like particles, a novel nanomaterial for tumor targeting. Journal of Nanobiotechnology 4 (2006).

https://doi.org/10.1186/1477-3155-4-2

[53] H. Masarapu, B. K. Patel, P. L. Chariou, H. Hu, N. M. Gulati, B. L. Carpenter, R. A. Ghiladi, S. Shukla, N. F. Steinmetz, Physalis Mottle Virus-Like Particles as Nanocarriers for 
Imaging Reagents and Drugs. Biomacromolecules 18 (2017) 4141-4153.

https://doi.org/10.1021/acs.biomac.7b01196

[54] K. G. Patel, J. R. Swartz, Surface Functionalization of Virus-Like Particles by Direct Conjugation Using Azide-Alkyne Click Chemistry. Bioconjugate Chem 22 (2011) 376-387. https://doi.org/10.1021/bc100367u

[55] H. Lee, C. E. Benjamin, C. M. Nowak, L. H. Tuong, R. P. Welch, Z. Chen, M.

Dharmarwardana, K. W. Murray, L. Bleris, S. D’Arcy, J. J. Gassensmith, Regulating the Uptake of Viral Nanoparticles in Macrophage and Cancer Cells via a pH Switch. Mol. Pharmaceutics 15 (2018) 2984-2990. https://doi.org/10.1021/acs.molpharmaceut.8b00348

[56] Q. X. Thong, R. Biabanikhankahdani, K. L. Ho, N. B. Alitheen, W. S. Tan, Thermallyresponsive Virus-like Particle for Targeted Delivery of Cancer Drug. Scientific Reports 9 (2019) 3945. https://doi.org/10.1038/s41598-019-40388-X

[57] G. Destito, R. Yeh, C. S. Rae, M. G. Finn, M. Manchester, Folic Acid-Mediated Targeting of Cowpea Mosaic Virus Particles to Tumor Cells. Chemistry \& Biology 14 (2007) 1152-1162. https://doi.org/10.1016/j.chembiol.2007.08.015

[58] A. A. Aljabali, S. Shuckla, G. P. Lomonossoff, N.F. Steinmetz, D. J. Evans, CPMV-DOX delivers. Mol Pharm. 10 (2013) 3-10. https://doi.org/10.1021/mp3002057

[59] R. A. Miller, A. D. Presley., M. B. Francis, Self-Assembling Light-Harvesting Systems from Synthetically Modified Tobacco Mosaic Virus Coat Proteins. J. Am. Chem. Soc. 129 (2007) 3104-3109. https://doi.org/10.1021/ja063887t

[60] C, K. Simon, T. Klose, S. Herbst, B. G. Han, A. Sinz, R. M. Glaeser, M. T. Stubbs, H, Lillie, Disulfide linkage and structure of highly stable yeast-derived virus-like particles of murine polyomavirus. J Biol. Chem. 289 (2014) 10411-10418.

https://doi.org/10.1074/jbc.M113.484162

[61] S. Kobayashi, T. Suzuki, M. Igarashi, Y. Orba, N. Ohtake, K. Nagakawa, K. Niikura, T.

Kimura, H. Kasamatsu, H. Sawa, Cysteine Residues in the Major Capsid Protein, Vp1, of the JC Virus Are Important for Protein Stability and Oligomer Formation. PLoS ONE 8 (2013) e76668. https://doi.org/10.1371/journal.pone.0076668

[62] M. W. Jones, R. A. Strickland, F. F. Schumacher, S. Caddick, J. R. Baker, M. I. Gibson, D. M. Haddleton, Polymeric Dibromomaleimides as Extremely Efficient Disulfide Bridging Bioconjugation and Pegylation Agents. JACS 134 (2012) 1847-1852. https://doi.org/10.1021/ja210335f

[63] Z. Chen, S. Li, M. Dharmarwardana, A. Schlimme, J. J Gassensmith, Viral chemistry: the chemical functionalization of viral architectures to create new technology. Wiley Interdiscipl Rev. Nanomed. Nanobiotechnol. 8 (2016) 512-534. https://doi.org/10.1002/wnan.1379 [64] Z. Chen, S.D. Boyd, J. S. Calvo, K. W. Murray, G. L. Mejia, C. E. Benjamin, R. P. Welch, D. D. Winkler, G. Meloni, S. D’Arcy, J. J. Gassensmith, Fluorescent Functionalization across Quaternary Structure in a Virus-like Particle. Bioconjugate Chem 28 (2017) 2277-2283. https://doi.org/10.1021/acs.bioconjchem.7b00305

[65] J. A. Finbloom, K. Han, C. C. Slack, A. L. Furst, and M. B. Francis, Cucurbit[6]urilPromoted Click Chemistry for Protein Modification. J. Am. Chem. Soc. 139 (2017) 9691-9697. https://doi.org/10.1021/jacs.7b05164

[66] E. Strable, D. E. Prasuhn Jr., A. K. Udit, S. Brown, A. J. Link, J. T. Ngo, G. Lander, J. Quispe, C. S. Potter, B. Carragher, D. A. Tirrell, M. G. Finn, Unnatural Amino Acid Incorporation into Virus-Like Particles. Bioconjugate Chem. 19 (2008) 866-875. https://doi.org/10.1021/bc700390r 
[67] J. Neburkova, F. Sedlack, J. Zackova Suchanova, L. Kostka, P. Sacha, V. Subr, T. Etrych, P. Simon, J. Barinkova, R. Krystufek, H. Spanielova, J. Forstova, J. Konvalinka, P. Cigler, Inhibitor-GCPII Interaction: Selective and Robust System for Targeting Cancer Cells with Structurally Diverse Nanoparticles, Mol. Pharmaceutics 15 (2018) 2932-2945.

https://doi.org/10.1021/acs.molpharmaceut.7b00889.

[68] X. Wu, J. Ye, A. T. DeLaitsch, Z. Rashidijahanabad, S. Lang, T. Kakeshpour, Y. Zhao, S. Ramadan, P. V. Saavedra, V. Yuzbasiyan-Gurkan, H. Kavunja, H. Cao, J. C. Gildersleeve, X. Huang, Chemoenzymatic Synthesis of 9NHAc-GD2 Antigen to Overcome the Hydrolytic Instability of O-Acetylated-GD2 for Anticancer Conjugate Vaccine Development, Angew. Chem. 133 (2021) 2-12. https://doi.org/10.1002/anie.202108610.

[69] S. Tang, B. Xuan, X. Ye, Z. Huang, Z. Qian, A Modular Vaccine Development Platform Based on Sortase-Mediated Site-Specific Tagging of Antigens onto Virus-Like Particles, Sci. Rep. 6 (2016) 25741. https://doi.org/10.1038/srep25741.

[70] D. Patterson, B. Schwarz, J. Avera, B. Western, M. Hicks, P. Krugler, M. Terra, M. Uchida, K. McCoy, T. Douglas, Sortase-Mediated Ligation as a Modular Approach for the Covalent Attachment of Proteins to the Exterior of the Bacteriophage P22 Virus-like Particle, Bioconjug. Chem. 28 (2017) 2114-2124. https://doi.org/10.1021/acs.bioconjchem.7b00296.

[71] X. Dai, A. Böker, U. Glebe, Broadening the scope of sortagging, RSC Adv. 9 (2019) 47004721. https://doi.org/10.1039/C8RA06705H.

[72] X. Chen, J. L. Zaro, W.-C. Shen, Fusion Protein Linkers: Property, Design and Functionality, Adv. Drug Deliv. Rev. 65 (2013) 1357-1369.

https://doi.org/10.1016/j.addr.2012.09.039.

[73] A. Gabizon, H. Shmeeda, A. T. Horowitz, S. Zalipsky, Tumor cell targeting of liposomeentrapped drugs with phospholipid-anchored folic acid-PEG conjugates, Adv. Drug Deliv. Rev. 56 (2004) 1177-1192. https://doi.org/10.1016/j.addr.2004.01.011.

[74] M. Cotten, E. Wagner, K. Zatloukal, M. L. Birnstiel, Chicken adenovirus(CELO virus) particles augment receptor-mediated DNA delivery to mammalian cells and yield exceptional levels of stable transformants, J. Virol. 67 (1993) 3777-3785.

https://doi.org/10.1128/jvi.67.7.3777-3785.1993.

[75] C. E. Ashley, E. C. Carnes, G. K. Phillips, P. N. Durfee, M. D. Buley, C. A. Lino, D. P. Padilla, B. Phillips, M. B. Carter, C. L. Willman, C. J. Brinker, J. do Carmo Caldeira, B. Chackerian, W. Wharton, D. S. Peabody, Cell-Specific Delivery of Diverse Cargos by Bacteriophage MS2 Virus-like Particles, ACS Nano 5 (2011) 5729-5745.

https://doi.org/10.1021/nn201397z.

[76] A. Jegerlehner, T. Storni, G. Lipowsky, M. Schmid, P. Pumpens, M. F. Bachmann, Regulation of IgG antibody responses by epitope density and CD21-mediated costimulation, Eur. J. Immunol. 32 (2002) 3305-3314. https://doi.org/10.1002/1521-

4141(200211)32:11<3305::AID-IMMU3305>3.0.CO;2-J.

[77] M. Dharmarwardana, A. F. Martins, Z. Chen, P. M. Palacios, C. M. Nowak, R. P. Welch, S. Li, M. A. Luzuriaga, L. Bleris, B. S. Pierce, A. D. Sherry, J. J. Gassensmith, Nitroxyl Modified Tobacco Mosaic Virus as a Metal-Free High-Relaxivity MRI and EPR Active Superoxide Sensor, Mol. Pharmaceutics 15 (2018) 2973-2983. https://doi.org/10.1021/acs.molpharmaceut.8b00262.

[78] B. Mansoori, A. Mohammadi, M. Amin Doustvandi, F. Mohammadnejad, F. Kamari, M. F. Gjerstorff, B. Baradaran, M. R. Hamblin, Photodynamic therapy for cancer: Role of natural 
products, Photodiagnosis Photodyn. Ther. 26 (2019) 395-404.

https://doi.org/10.1016/j.pdpdt.2019.04.033.

[79] H. S. Han, K. Y. Choi, Advances in Nanomaterial-Mediated Photothermal Cancer

Therapies: Toward Clinical Applications, Biomedicines 9 (2021) 305.

https://doi.org/10.3390/biomedicines 9030305 .

[80] U. Chitgupi, Y. Qin, J. F. Lovell, Targeted Nanomaterials for Phototherapy,

Nanotheranostics 1 (2017) 38-58. https://www.doi.org/10.7150/ntno.17694.

[81] H. S. Kim, L. D. Y. Lee, Near-Infrared-Responsive Cancer Photothermal and Photodynamic Therapy Using Gold Nanoparticles, Polymers 10 (2018) 961.

https://doi.org/10.3390/polym10090961.

[82] J. Li, W. Zhang, W. Ji, J. Wang, N. Wang, W. Wu, Q. Wu, X. Hou, W. Hu, L. Li, Near infrared photothermal conversion materials: mechanism, preparation, and photothermal cancer therapy applications, J. Mater. Chem. B 9 (2021) 7909-7926.

https://doi.org/10.1039/D1TB01310F.

[83] J. H. Correia, J. A. Rodrigues; S. Pimenta, T. Dong, Z. Yang, Photodynamic Therapy Review: Principles, Photosensitizers, Applications, and Future Directions, Pharmaceutics 13 (2021) 1332. https://doi.org/10.3390/pharmaceutics13091332.

[84] H. Abrahamse, M. R. Hamblin, New photosensitizers for photodynamic therapy, Biochem.

J. 473 (2016) 347-364. https://doi.org/10.1042/BJ20150942.

[85] X. Xu, H. Lu, R. Lee, Near Infrared Light Triggered Photo/Immuno-Therapy Toward

Cancers, Front. Bioeng. Biotechnol. 8 (2020) 488. https://doi.org/10.3389/fbioe.2020.00488.

[86] F. Zhou, J. Yang, Y. Zhang, M. Liu, M. L. Lang, M. Li, W. R. Chen, Local Phototherapy

Synergizes with Immunoadjuvant for Treatment of Pancreatic Cancer through Induced

Immunogenic Tumor Vaccine, Clin. Cancer Res. 24 (2018) 5335-5346.

https://www.doi.org/10.1158/1078-0432.CCR-18-1126.

[87] S. Shukla, H. Hu, H. Cai, S.-K. Chan, C. E. Boone, V. Beiss, P. L. Chariou, N. F. Steinmetz, Plant Viruses and Bacteriophage-Based Reagents for Diagnosis and Therapy, Annu. Rev. Virol. 7 (2020) 559-87. https://doi.org/10.1146/annurev-virology-010720-052252.

[88] S. Lin, C. Liu, X. Han, H. Zhong, C. Cheng, Viral Nanoparticle System: An Effective Platform for Photodynamic Therapy, Int. J. Mol. Sci. 22 (2021) 1728.

https://doi.org/10.3390/ijms22041728.

[89] C. E. Benjamin, Z. Chen, P. Kang, B. A. Wilson, N. Li, S. O. Nielsen, Z. Qin, J. J. Gassensmith, Site-Selective Nucleation and Size Control of Gold Nanoparticle Photothermal Antennae on the Pore Structures of a Virus, J. Am. Chem. Soc. 140 (2018) 17226-17233. https://doi.org/10.1021/jacs.8b10446.

[90] J. K. Rhee, M. Baksh, C. Nycholat, J. C. Paulson, H. Kitagishi, M. G. Finn, Glycan-targeted virus-like nanoparticles for photodynamic therapy, Biomacromolecules 13 (2012) 2333-2338. https://doi.org/10.1021/bm300578p.

[91] A. D. Waldman, J. M. Fritz, M. J. Lenardo, A guide to cancer immunotherapy: from T cell basic science to clinical practice, Nat. Rev. Immunol. 20 (2020) 651-668. https://doi.org/10.1038/s41577-020-0306-5.

[92] Y. Zhang, Z. Zhang, The history and advances in cancer immunotherapy: understanding the characteristics of tumor-infiltrating immune cells and their therapeutic implications, Cell Mol. Immunol. 17 (2020) 807-821. https://doi.org/10.1038/s41423-020-0488-6. [93] J. Zepeda-Cervantes, J. O. Ramírez-Jarquín, L. Vaca, Interaction Between Virus-Like Particles (VLPs) and Pattern Recognition Receptors (PRRs) From Dendritic Cells (DCs): 
Toward Better Engineering of VLPs. Front. Immunol. 11 (2020) 1100.

https://doi.org/10.3389/fimmu.2020.01100.

[94] M. O. Mohsen, A. C. Gomes, G. Cabral-Miranda, C. Krueger, F. M. Leoratti, J. V. Stein, M. F. Bachmann, Delivering adjuvants and antigens in separate nanoparticles eliminates the need of physical linkage for effective vaccination. Journal of Controlled Release. 251 (2017) 92-100. https://doi.org/10.1016/j.jconrel.2017.02.031.

[95] J. C. Mbongue, H. A. Nieves, T. W. Torrez, W. H. R. Langridge, The Role of Dendritic Cell Maturation in the Induction of Insulin-Dependent Diabetes Mellitus. Front. Immunol. 8 (2017) 327. https://doi.org/10.3389/fimmu.2017.00327.

[96] M. Bachmann, G. Jennings, Vaccine delivery: a matter of size, geometry, kinetics and molecular patterns. Nat. Rev. Immunol. 10 (2010) 787-796. https://doi.org/10.1038/nri2868. [97] W. Liao, Z. Hua, C. Liu, L. Lin, R. Chen, B. Hou, Characterization of T-Dependent and TIndependent B Cell Responses to a Virus-like Particle. The Journal of Immunology. 198 (2017) 3846-3856. https://doi.org/10.4049/jimmunol.1601852.

[98] R. Cubas, Z. Sheng, S. Kwon, E. M. Sevick-Muraca, et al., Virus-like particle (VLP) lymphatic trafficking and immune response generation after immunization by different routes. $\mathrm{J}$ Immunother. 32 (2009) 118-128. https://doi.org/10.1097/CJI.0b013e31818f13c4.

[99] K. L. Knutson, M. L. Disis, Tumor antigen-specific T helper cells in cancer immunity and immunotherapy. Cancer Immunol Immunother. 54 (2005) 721-8. https://doi.org/10.1007/s00262004-0653-2.

[100] L. Delamarre, H. Holcombe, I. Mellman, Presentation of Exogenous Antigens on Major Histocompatibility Complex (MHC) Class I and MHC Class II Molecules Is Differentially Regulated during Dendritic Cell Maturation. J Exp. Med. 198 (2003) 111-122.

https://doi.org/10.1084/jem.20021542.

[101] S. K. Datta, E. Raz, Induction of antigen cross-presentation by Toll-like receptors. Springer Semin Immunopathol. 26 (2004) 247-55. https://doi.org/10.1007/s00281-004-01742. [102] J. Wang, Y. Li, G. Nie, Multifunctional biomolecule nanostructures for cancer therapy. Nat. Rev. Mater. 6 (2021) 766-783. https://doi.org/10.1038/s41578-021-00315-X.

[103] C. Hou, H. Xu, X. Jiang, Y. Li, S. Deng, M. Zang, J. Xu, and J. Liu, Virus-Based Supramolecular Structure and Materials: Concept and Prospects. ACS Appl. Bio. Mater. 4 (2021) 5961-5974. https://doi.org/10.1021/acsabm.1c00633.

[104] A. B. Gautam, V. Beiss, C. Wang, L. Wang, N. F. Steinmetz, Plant Viral Nanoparticle Conjugated with Anti-PD-1 Peptide for Ovarian Cancer Immunotherapy. Int. J. Mol. Sci. 22 (2021) 9733. https://doi.org/10.3390/ijms22189733.

[105] P. H. Lizotte, A. M. Wen, M. R. Sheen, et al., In situ vaccination with cowpea mosaic virus nanoparticles suppresses metastatic cancer. Nature Nanotech. 11 (2016) 295-303. https://doi.org/10.1038/nnano.2015.292.

[106] A. A. Murray, C. Wang, S. Fiering, N. F. Steinmetz, In Situ Vaccination with Cowpea vs Tobacco Mosaic Virus against Melanoma. Mol. Pharm. 15 (2018) 3700-3716.

https://doi.org/10.1021/acs.molpharmaceut.8b00316.

[107] X. Wu, C. McKay, C. Pett, J. Yu, M. Schorlemer, S. Ramadan, S. Lang, S. Behren, U. Westerlind, M. G. Finn, X. Huang, Synthesis and Immunological Evaluation of Disaccharide Bearing MUC-1 Glycopeptide Conjugates with Virus-like Particles. ACS Chem. Biol. 14 (2019) 2176-2184. https://doi.org/10.1021/acschembio.9b00381. 
[108] F. Zabel, T. M. Kündig, M. F. Bachmann, Virus-induced humoral immunity: on how B cell responses are initiated. Curr Opin Virol. 3 (2013) 357-62.

https://doi.org/10.1016/j.coviro.2013.05.004.

[109] C. Qian, X. Liu, Q. Xu, Z. Wang, J. Chen, T. Li, Q. Zheng, H. Yu, Y. Gu, S. Li, N. Xia, Recent Progress on the Versatility of Virus-Like Particles. Vaccines. 8 (2020) 139. https://doi.org/10.3390/vaccines8010139.

[110] A. Palladini, S. Thrane, C. M. Janitzek, et al., Virus-like particle display of HER2 induces potent anti-cancer responses. Oncoimmunology 7 (2018).

https://doi.org/10.1080/2162402X.2017.1408749.

[111] S. N. Crooke, J. Schimer, I. Raji, B. Wu, A. K. Oyelere, M. G. Finn, Lung Tissue Delivery of Virus-Like Particles Mediated by Macrolide Antibiotics. Mol. Pharmaceutics. 16 (2019) 2947-2955. https://doi.org/10.1021/acs.molpharmaceut.9b00180.

[112] M. O. Mohsen, A. C. Gomes, G. Cabral-Miranda, C. Krueger, F. M. Leoratti, J. V. Stein, M. F. Bachmann, Delivering adjuvants and antigens in separate nanoparticles eliminates the need of physical linkage for effective vaccination. Journal of Controlled Release. 251 (2017) 92-100. https://doi.org/10.1016/j.jconrel.2017.02.031.

[113] P. Lam, N. F. Steinmetz, Delivery of siRNA therapeutics using cowpea chlorotic mottle virus-like particles. Biomaterials Science. 7 (2019) 3138-3142.

https://doi.org/10.1039/C9BM00785G.

[114] F. C. Herbert, O. R. Brohlin, T. Galbraith, C. Benjamin, C.A. Reyes, M. A. Luzuriaga, A. Shahrivarkevishahi, and J. J. Gassensmith, Supramolecular Encapsulation of Small-Ultrared Fluorescent Proteins in Virus-Like Nanoparticles for Noninvasive In Vivo Imaging Agents. Bioconjugate Chem. 31 (2020) 1529-1536. https://doi.org/10.1021/acs.bioconjchem.0c00190. [115] L. Lavelle, J.P. Michel, M. Gingery, The disassembly, reassembly and stability of CCMV protein capsids. Journal of Virology. 146 (2007) 311-316.

https://doi.org/10.1016/j.jviromet.2007.07.020.

[116] M. V. Villagrana-Escareño, E. Reynaga-Hernández, O. G. Galicia-Cruz, A. L. DuránMeza, V. D. L. Cruz-González, C. Y. Hernández-Carballo, and J. Ruíz-García, VLPs Derived from the CCMV Plant Virus Can Directly Transfect and Deliver Heterologous Genes for Translation into Mammalian Cells. BioMed Research International. (2019). https://doi.org/10.1155/2019/4630891.

[117] O. Azizgolshani, R. F. Garmann, R. Cadena-Nava, C. M. Knobler, W. M. Gelbart, Reconstituted plant viral capsids can release genes to mammalian cells. Virology. 441 (2013) 1217. https://doi.org/10.1016/j.virol.2013.03.001.

[118] R. D. Cadena-Nava, M. Comas-Garcia, R. F. Garmann, A. L. N. Rao, C. M. Knobler, and W. M. Gelbart, Self-Assembly of Viral Capsid Protein and RNA Molecules of Different Sizes:

Requirement for a Specific High Protein/RNA Mass Ratio. J. Virol. 86 (2012) 3318-3326. https://doi.org/10.1128/JVI.06566-11.

[119] F. A. Galaway, P. G. Stockley, MS2 Viruslike Particles: A Robust, Semisynthetic Targeted Drug Delivery Platform. Mol. Pharmaceutics. 10 (2013) 59-68. https://doi.org/10.1021/mp3003368.

[120] W. M. Aumiller Jr., M. Uchida, T. Douglas, Protein cage assembly across multiple length scales. Chem. Soc. Rev. 47 (2018) 3433-3469. https://doi.org/10.1039/C7CS00818J.

[121] J. E. Glasgow, S. L. Capeheart, M. B. Francis, and D. Tullman-Ercek, OsmolyteMediated Encapsulation of Proteins inside MS2 Viral Capsids. ACS Nano. 6 (2012) 8658-8664. https://doi.org/10.1021/nn302183h. 
[122] J. K. Rhee, M. Hovlid, J. D. Fiedler, S. D. Brown, F. Manzenrieder, H. Kitagishi, C. Nycholat, J. C. Paulson, M.G. Finn Colorful Virus-Like Particles: Fluorescent Protein Packaging by the Q $\beta$ Capsid. Biomacromolecules. 12 (2011) 3977-3981.

https://doi.org/10.1021/bm200983k.

[123] M. Wu, W. L. Brown, P. G. Stockley, Cell-Specific Delivery of Bacteriophage-

Encapsidated Ricin A Chain. Bioconjugate Chem. 6 (1995) 587-595.

https://doi.org/10.1021/bc00035a013.

[124] J. D. Fiedler, S. D. Brown, J. L. Lau, M. G. Finn, RNA-Directed Packaging of Enzymes within Virus-like Particles. Angew. Chem. Int. Ed. 49 (2010) 9648-9651. https://doi.org/10.1002/anie.201005243.

[125] C. E. Franke, A. E. Czapar, R. B. Patel, and N. F. Steinmetz, Tobacco Mosaic VirusDelivered Cisplatin Restores Efficacy in Platinum-Resistant Ovarian Cancer Cells. Mol Pharm. 15 (2018) 2922-2931. https://doi.org/10.1021/acs.molpharmaceut.7b00466.

[126] M. Wu, T. Sherwin, W. L. Brown, P. G. Stockley, Delivery of antisense oligonucleotides to leukemia cells by RNA bacteriophage capsids. Nanomedicine: Nanotechnology, Biology and Medicine. 1 (2005) 67-76. https://doi.org/10.1016/j.nano.2004.11.011.

[127] J. B. Bancroft, G. J. Hills, R. A. Markham, Study of the Self-Assembly Process in a Small Spherical Virus. Formation of Organized Structures from Protein Subunits in Vitro. Virology. 31 (1967) 354-379. https://doi.org/10.1016/0042-6822(67)90180-8.

[128] T. Douglas, M. Young, Host-Guest Encapsulation of Materials by Assembled Virus Protein Cages. Nature. 393 (1998), 152-155. https://doi.org/10.1038/30211.

[129] A. Prel, V. Cavel, R. Gayon, P. Ravassard, C. Duthoit, E. Payen, L. Maouche-Chretien, A. Creneguy, Tuan Huy, Nguyen, Nicolas Martin, Eric Piver, Raphaël Sevrain, Lucille Lamouroux, P. Leboulch, F. Deschaseaux, P. Bouillé, L. Sensébé, J. Pagès, Highly efficient in vitro and in vivo delivery of functional RNAs using new versatile MS2-chimeric retrovirus-like particles. Mol. Ther. Methods. Clin. Dev. 2 (2015) 15039. https://doi.org/10.1038/mtm.2015.39. [130] J. Li, Y. Sun, T. Jia, R. Zhang, K. Zhang, L. Wang, Messenger RNA vaccine based on recombinant MS2 virus-like particles against prostate cancer. Int. J. Cancer. 134 (2014) 16831694. https://doi.org/10.1002/ijc.28482.

[131] Y. Pan, Y. Zhang, T. Jia, K. Zhang, J. Li, L. Wang, Development of a microRNA delivery system based on bacteriophage MS2 virus-like particles. FEBS. J. 279 (2012) 1198-1208. https://doi.org/10.1111/j.1742-4658.2012.08512.X.

[132] Y. Pan, T. Jia, Y. Zhang, K. Zhang, R. Zhang, J. Li, and L. Wang, MS2 VLP-based delivery of microRNA-146a inhibits autoantibody production in lupus-prone mice. Int. J. Nanomedicine. 7 (2012) 5957-5967. https://doi.org/10.2147/IJN.S37990.

[133] Y. Yao, T. Jia, Y. Pan, H. Gou, Yu. Li, Y. Sun, R. Zhang, K. Zhang, G. Lin, J. Xie, J. Li, L Wang, Using a Novel MicroRNA Delivery System to Inhibit Osteoclastogenesis. Int. J. Mol. Sci. 4 (2015) 8337-8350. https://doi.org/10.3390/ijms16048337.

[134] S. Qazi, H. M. Miettinen, R. A. Wilkinson, K. McCoy, T. Douglas, B. Wiedenheft, Programmed Self-Assembly of an Active P22-Cas9 Nanocarrier System

Mol. Pharmaceutics. 13 (2016) 1191-1196. https://doi.org/10.1021/acs.molpharmaceut.5b00822 [135] J. Daley, Gene Therapy Arrives. Nature. 576 (2019).

[136] B. J. Aubrey, G. L. Kelly, A. Janic, M. J. Herold, A. Strasser, How does p53 induce apoptosis and how does this relate to p53-mediated tumour suppression? Cell Death Differ. 25 (2018) 104-113. https://doi.org/10.1038/cdd.2017.169. 
[137] W. Zhang, L. Li, D. Li, J. Liu, X. Li, W. Li, X. Xu, M. J. Zhang, L. A. Chandler, H. Lin, A. Hu, W. Xu, D. M. Lam, The First Approved Gene Therapy Product for Cancer Ad-p53 (Gendicine): 12 Years in the Clinic. Hum. Gene Ther. 29 (2018) 160-179.

https://doi.org/10.1089/hum.2017.218

[138] D. Cross, J. K. Burmester, Gene Therapy for Cancer Treatment: Past, Present and Future. Clin. Med. Res. 3 (2006) 218-227. https://doi.org/10.3121/cmr.4.3.21

[139] A. Shahryari, M. S. Jazi, S. Mohammadi, H. R. Nikoo, Z. Nazari, E. S. Hosseini, I. Burtscher, S. J. Mowla, H. Lickert, Development and Clinical Translation of Approved Gene Therapy Products for Genetic Disorders. Front. Genet. 10 (2019) 868. https://doi.org/10.3389/fgene.2019.00868 [140] A. Shahryari, I. Burtscher, Z. Nazari, H. Lickert, Engineering Gene Therapy: Advances and Barriers. Adv. Therap. 4 (2021). https://doi.org/10.1002/adtp.202100040.

[141] X. Ma, J. L. Xu, Y. Jia, Y. Zhang, W. Wang, C. Li, W. He, S. Zhou, B. Zhang, Enhance transgene responses through improving cellular uptake and intracellular trafficking by bioinspired non-viral vectors. J. Nanobiotechnol. 18 (2020). https://doi.org/10.1186/s12951-020$\underline{0582-\mathrm{z}}$

[142] C. Jreyssaty, Q. Shi, H. Wang, X. Qiu, F. M. Winnik, X. Zhang, K. Dai, M. Benderdour, J. C. Fernandes, Efficient Nonviral Gene Therapy Using Folate-Targeted Chitosan-DNA Nanoparticles In Vitro. ISRN Pharm. 2012. https://doi.org/10.5402/2012/369270 [143] J. Villemejane, L. M. Mir, Physical methods of nucleic acid transfer: general concepts and applications. Br. J. Pharmocol. 157 (2009) 207-219. https://doi.org/10.1111/j.14765381.2009.00032.x

[144] T. M. Belete, The Current Status of Gene Therapy for the Treatment of Cancer. Biologics. 15 (2021) 67-77. https://doi.org/10.2147/BTT.S302095

[145] M.E. Carrion, M. Menger, A. Wool, J. Smith, I. Kovesdi, Adenovirus Production, Toxicity and Tropism. Molecular Therapy. 3 (2001) S157-S174. https://doi.org/10.1006/mthe.2001.0383 [146] S. Lehrman, Virus treatment questioned after gene therapy death. Nature, 401 (1999) 517518. https://doi.org/10.1038/43977

[147] T. Storni, C.Ruedl, K. Schwarz, R. A. Schwendener, W. A. Renner, M. F. Bachmann, Nonmethylated CG Motifs Packaged into Virus-Like Particles Induce Protective Cytotoxic T Cell Responses in the Absence of Systemic Side Effects. J. Immunol. 172 (2004) 1777-1785. https://doi.org/10.4049/jimmunol.172.3.1777

[148] L. Chang, G.Wang, T. Jia, L. Zhang,Y. Li, Y. Han, K. Zhang, G. Lin, R. Zhang, J. Li and L. Wang, Armored long non-coding RNA MEG3 targeting EGFR based on recombinant MS2 bacteriophage virus-like particles against hepatocellular carcinoma. Oncotarget, 7 (2016) 2398824004. https://doi.org/10.18632/oncotarget.8115

[149] R. Oun, Y.E. Moussa, N. J. Wheate, The side effects of platinum-based chemotherapy drugs: a review for chemists. Dalton Trans. 47 (2018) 6645-6653.

https://doi.org/10.1039/c8dt00838h

[150] H. L. Wong, R. Bendayan, A. M. Rauth, Y. Li, X. Y. Wu, Chemotherapy with anticancer drugs encapsulated in solid lipid nanoparticles. Adv. Drug Deliv. Rev. 59 (2007) 491-504. https://doi.org/10.1016/j.addr.2007.04.008

[151] S. S. Feng, Nanoparticles of biodegradable polymers for new-concept chemotherapy. Expert Review of Medical Devices, 1 (2004) 115-125. https://doi.org/10.1586/17434440.1.1.115 [152] M. J. Rohovie, M. Nagasawa., J. R. Swartz, Virus-like particles: Next-generation nanoparticles for targeted therapeutic delivery. Bioengineering \& Translational Medicine, 2 (2016) 43-57. https://doi.org/10.1002/btm2.10049 
[153] T. Douglas, M. Young, Viruses: Making Friends with Old Foes. Science, 312 (2006) 873875. https://doi.org/10.1126/science. 1123223

[154] Y. Ma, R.J. M. Nolte, J.J.L.M. Cornelissen, Virus-based nanocarriers for drug delivery. Advanced Drug Delivery Reviews, 64 (2012) 811-825.

https://doi.org/10.1016/j.addr.2012.01.005

[155] M. L. Hovlid, J. L. Lau, K. Breitenkamp, C. J. Higginson, B. Laufer, M. Manchester, and M. G. Finn, Encapsidated Atom-Transfer Radical Polymerization in Q $\beta$ Virus-like Nanoparticles. ASC Nano, 8 (2014) 8003-8014. https://doi.org/10.1021/nn502043d [156] W. H. Roos, I. L. Ivanovska, A. Evilevitch, G. J. Wuite, Viral capsids: Mechanical characteristics, genome packaging and delivery mechanisms. Cellular and Molecular Life Sciences, 64 (2007) 1484. https://doi.org/10.1007/s00018-007-6451-1 [157] I. Yildiz, K. L. Lee., K. Chen, S. Shukla, N. F.Steinmetz, Infusion of imaging and therapeutic molecules into the plant virus-based carrier cowpea mosaic virus: Cargo-loading and delivery. Journal of Controlled Release, 172 (2013) 568-578.

https://doi.org/10.1016/j.jconrel.2013.04.023 